\title{
Melanin-Binding Colorants: Updating Molecular Modeling, Staining and Labeling Mechanisms, and Biomedical Perspectives
}

\author{
Juan C. Stockert ${ }^{1,2, *} \mathbb{C}^{\mathbb{C}}$, Jesús Espada ${ }^{3}(\mathbb{D})$ and Alfonso Blázquez-Castro ${ }^{4} \mathbb{(}$
}

1 Facultad de Medicina, Instituto de Oncología “Angel H. Roffo", Area Investigación, Universidad de Buenos Aires, Avda. San Martin 5481, Buenos Aires C1417DTB, Argentina

2 Facultad de Ciencias Veterinarias, Cátedra de Histología y Embriología, Instituto de Investigación y Tecnología en Reproducción Animal (INITRA), Universidad de Buenos Aires, Avda. Chorroarín 280, Buenos Aires C1427CWO, Argentina

3 Institute for Health Research (IdiPAZ), La Paz University Hospital, 28034 Madrid, Spain; jespada1968@gmail.com

4 Departamento de Biología, Universidad Autónoma de Madrid, 28049 Madrid, Spain; alfonso.blazquez@uam.es

* Correspondence: jcstockert@fvet.uba.ar

Citation: Stockert, J.C.; Espada, J.; Blázquez-Castro, A. Melanin-Binding Colorants: Updating Molecular Modeling, Staining and Labeling Mechanisms, and Biomedical Perspectives. Colorants 2022, 1 , 91-120. https://doi.org/10.3390/ colorants1010007

Academic Editor: Anthony Harriman

Received: 30 December 2021

Accepted: 14 February 2022

Published: 24 February 2022

Publisher's Note: MDPI stays neutral with regard to jurisdictional claims in published maps and institutional affiliations.

Copyright: (C) 2022 by the authors. Licensee MDPI, Basel, Switzerland. This article is an open access article distributed under the terms and conditions of the Creative Commons Attribution (CC BY) license (https:// creativecommons.org/licenses/by/ $4.0 /)$.

\begin{abstract}
Melanin and melanoma tumors are two fields of increasing interest in biomedical research Melanins are ubiquitous biopigments with adaptive value and multiple functions, and occur in the malignant melanoma. Although several chemical structures have been proposed for eumelanin, molecular modeling and orbitals indicate that a planar or spiral benzoquinone-porphycene polymer would be the model that better explains the broad-band light and ultrasound absorption, electric conductivity, and graphite-like organization shown by X-ray crystallography and electron microscopy. Lysosomes and melanosomes are selectively labeled by vital probes, and melanin also binds to metal cations, colorants, and drugs, with important consequences in pharmacology, pathology, and melanoma therapy. In addition to traditional and recent oncologic treatments, photodynamic, photothermal, and ultrasound protocols represent novel modalities for melanoma therapy. Since eumelanin is practically the ideal photothermal and ultrasound sensitizer, the vibrational decay from photo-excited electrons after NIR irradiation, or the electrochemical production of ROS and radicals after ultrasound absorption, induce an efficient heating or oxidative response, resulting in the damage and death of tumor cells. This allows repetitive treatments due to the remaining melanin contained in tumoral melanophages. Given that evolution and prognosis of the advanced melanoma is still a concern, new biophysical procedures based on melanin properties can now be developed and applied.
\end{abstract}

Keywords: biological staining; eumelanin structure; intercalative binding; melanin ligands; melanosomes; melanoma therapy

\section{Introduction}

The study of interactions between small molecular ligands (colorants, drugs) and macromolecular substrates is a biomedical field of steadily growing interest and involves the chemical structure and properties of both components. The term colorant has a wider connotation than dye [1], but here both will be applied interchangeably. A colorant is defined as a substance that is used to impart color to another material [2]. Commonly, detailed physico-chemical features of small dye molecules are better known than those of biopolymers, and often the knowledge of dye-substrate binding mechanisms allows a deeper understanding of macromolecular structure.

The early history (discovery and development) of dyes and drugs is closely interwoven, establishing the foundations of modern chemotherapy [3]. Numerous dyes and their derivatives have found medical applications as diagnostic and therapeutic agents, and 
new dyes have been developed from the research on antiparasite diseases [4,5]. Thus, the azo dye chrysoidin led to the antibacterial $p$-sulfamido derivative (prontosil), some bisazo trypanocide dyes (Trypan red and blue) led to the discovery of arsenicals and aryl-urea derivatives (suramin) [6-8], etc. Other examples are antimalarial quinacrine and chloroquine, antibacterial acridines and triarylmethanes, antiseptic xanthenes, tumor-markering and psychotropic phenothiazines, antitumoral and antiviral photosensitizing (photodynamic) agents, antitrypanosomal aromatic diamidine fluorochromes, etc. [3,7,9-13].

On the other hand, the application of physico-chemical parameters to colorants (e.g., quantitative structure activity relationships, QSAR) has allowed explaining cell staining and labeling mechanisms, as well as to correct misleading chemical formulations, and to design new and improved probes and drugs [14-18]. As macromolecular substrate, melanin has been scarcely used to study staining processes, but at present a great interest is devoted to analyze the selective binding of some dyes and drugs to this remarkable cell component, which is probably the most ancient group of natural pigments. All Prokaryota and Eukaryota, the latter including Protista, Fungi, Plantae, and Animalia, have melanins [19-21].

Melanins are indole- and catechol-type biopolymers, and in mammals, indole-melanins correspond to eumelanin (brown-black) and pheomelanin (yellow-red). They occur mainly in the skin and derivatives, retinal pigmented epithelium, and central nervous system (neuromelanin, in the substantia nigra, locus coeruleus, and stria vascularis of the cochlea). In plants and fungi, melanins generally correspond to the catechol-type (allomelanins) [22]. Early and recent reviews deal with the main features of melanin chemistry, properties, and applications [19,23-33].

Melanocytes are dendritic cells derived from neuro-ectodermal melanoblasts that have migrated to the skin during vertebrate embryogenesis. They are observed in hair follicles, and within and near the basal layer of the epidermis interspersed between keratinocytes, with whom they form adherent junctions with 5-8 neighboring cells using E-cadherin molecules [34]. The biosynthesis of melanin occurs within melanosomes, which are round or oval organelles $(\sim 1 \mu \mathrm{m}$ in diameter) with a clear lysosomal lineage [35,36], and the pigment is then transferred to keratinocytes through dendritic processes. Within melanomas, in addition to melanocytes, melanin-containing macrophages (melanophages) show few to an abundance of variably sized pigmented lysosomal granules (compound melanosomes) often forming coarse and vacuolated structures [37]. Sepia melanin and melanoma melanosomes are also phagocytized by cultured keratinocytes [38].

The malignant melanoma is one of the most aggressive human tumors, showing high resistance to standard treatments. Melanoma also occurs in experimental, companion, and larger domestic animals [37,39-43]. Giemsa- or Papanicolaou-stained cell smears from melanoma aspirates and tumor imprints can be used for cytopathology diagnosis [37,44].

Although the molecular structure of eumelanin is still poorly known, an overwhelming evidence indicates that it corresponds to an indole polymer with a high degree of conjugated double bonds $[19,32]$. A model based in a benzoquinone-porphycene (BQPo) macrocycle has been suggested [45-47]. It could fulfill most characteristics of eumelanin [33], namely a graphite-like structure with broad-band light absorption, semi- and photo-conductivity, strong binding affinity for dyes and drugs, and electron microscopic and X-ray crystallographic features.

On the other hand, eumelanin has a striking affinity for binding to a great number of ligands, examples being colorants, drugs, heavy metals, toxic compounds, and other xenobiotics. In addition to provide a mechanism for elimination of dangerous agents in the skin, ligands can also improve some melanin properties that can be useful in melanoma treatments such as photodynamic (PDT), photothermal (PTT), and sonodynamic (sonoelectrochemical, SET) therapy [33]. When the precise melanin type is not referred, the simple name of melanin will be used along this review.

On account of the difficulty in successfully treating the malignant melanoma in advanced and metastatic stage [48], further studies on new therapeutic modalities based on chemical and physical approaches are still necessary. Due to the close relation between 
chemistry, properties, and implications of melanin in human diseases, the aim of this review is to summarize proposed molecular structures and binding mechanisms of colorants and drugs, as well as their consequences regarding melanoma therapy. New melanoma treatments need to be based on a deeper understanding of the molecular structure of melanin and its interaction with colorants and drugs. Therefore, in agreement with recently suggested rules and criteria for review articles [49], these themes based on molecular mechanics and orbitals will be here illustrated, also attempting to offer seminal perspectives for innovative therapeutic conceptions and developments.

\section{Molecular Structure of Eumelanin}

The detailed molecular structure of eumelanin is poorly known, although an overwhelming amount of evidence indicates that it corresponds to a highly conjugated aromatic polymer [19,32]. Previous and recent reviews on eumelanin have been published [32,50-53], but at present no agreement has been reached regarding its precise chemical structure. In spite of methodological limitations, several polymeric linear models from the precursors 3,4-dihydroxy-phenylalanine (DOPA), DHI, and IQ [32] have been proposed (Figure 1). Although the precursor dihydroxy-indole-2-carboxylic acid (DHICA) can also play a role in melanin biosynthesis, it has not taken into account in this work because of the limitation of using the C2 site for polymerization, and the paler color when compared with the DHI polymer. Dopamine (DA) is also a melanin precursor, and although synthetic poly-dopamine (PDA) melanin does not contain the 2-carboxylic group, its properties correspond to a true eumelanin [19].

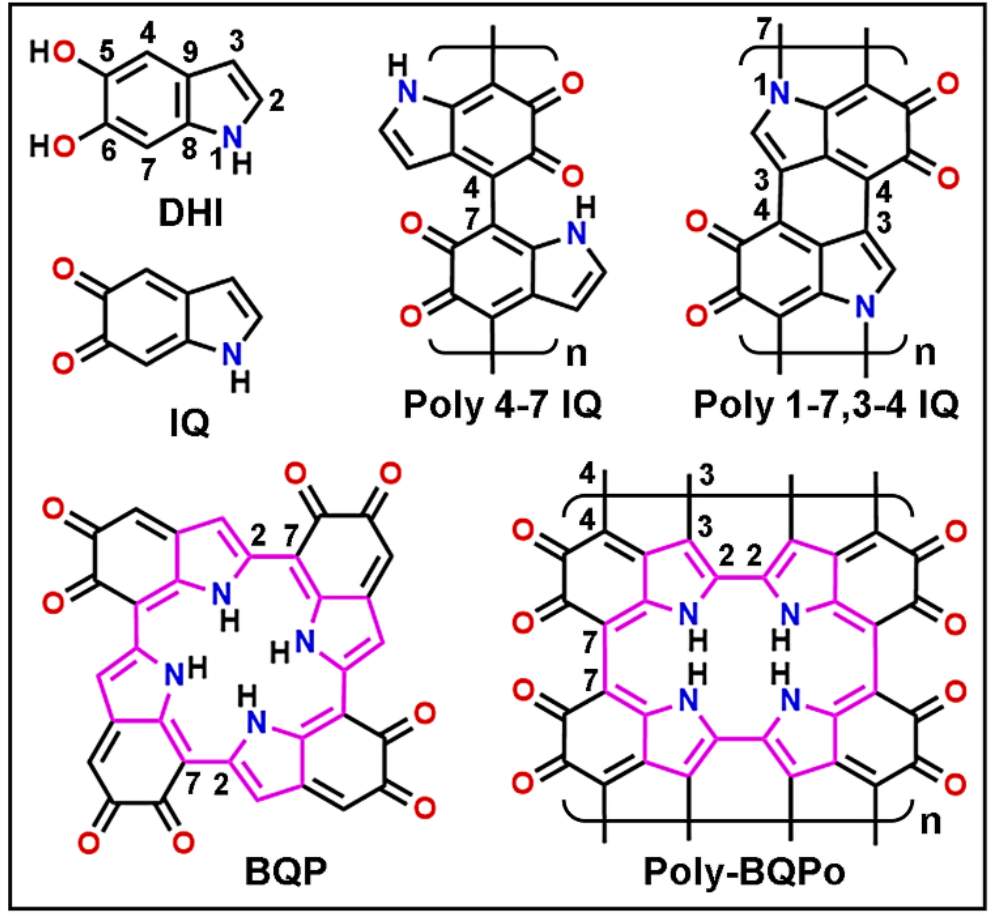

Figure 1. Chemical structure of the eumelanin precursors and polymers drawn with ChemDraw Ultra v12.0 software. Dihydroxy-indole (DHI) and indole-quinone (IQ) show atom numbering. Models of eumelanin polymers are also illustrated: linear flexible chain of poly 4-7 IQ [19,54], and planar rigid poly 1-7,3-4 IQ [55], as well as planar rigid models of benzoquinone-porphyrin (BQP, cyclic 2-7 IQ [56,57]), and benzoquinone-porphycene (poly-BQPo $[33,45,47])$, with porphyrin and porphycene represented as violet rings.

Possible models of eumelanin polymers are a linear flexible poly 4-7 IQ [19,54], a planar rigid poly 1-7,3-4 IQ [55]), a planar tetramer of a benzoquinone-porphyrin (BQP, cyclic 2-7 IQ [56,57]), and a benzoquinone-porphycene (poly-BQPo [33,45,47]). In contrast 
with flexible chain models for eumelanin, which have been recently reviewed [32], the poly-BQPo model based in the 2,2'-IQ dimer and the resulting 7-7 tetramer has been first described [45,46] and recently revisited [47]. In this model (Figure 1), the building block is either a benzoquinone (BQ) or benzocatechol $(\mathrm{BC})$ derivative of the porphycene ring (Po), which is a structural isomer of the porphyrin ring. A possible synthesis mechanism based on radical precursors has been described [33]. Taking into account the reactive C2, C3, C4, and C7 on IQ or DHI units, it can be expected that a polymer with all these sites forming covalent bonds with other units would be the most favorable and stable structure. This rationale is just satisfied for the BQPo model, in which these carbons are involved in polymerization (see Figure 1).

Chemical structures of melanin monomers are presented in Figure 2, showing formal, mesomeric, and $\pi^{*}$-conjugated structure of the precursor IQ, as well as the formation of hydrated IQ and ether DHI dimer.

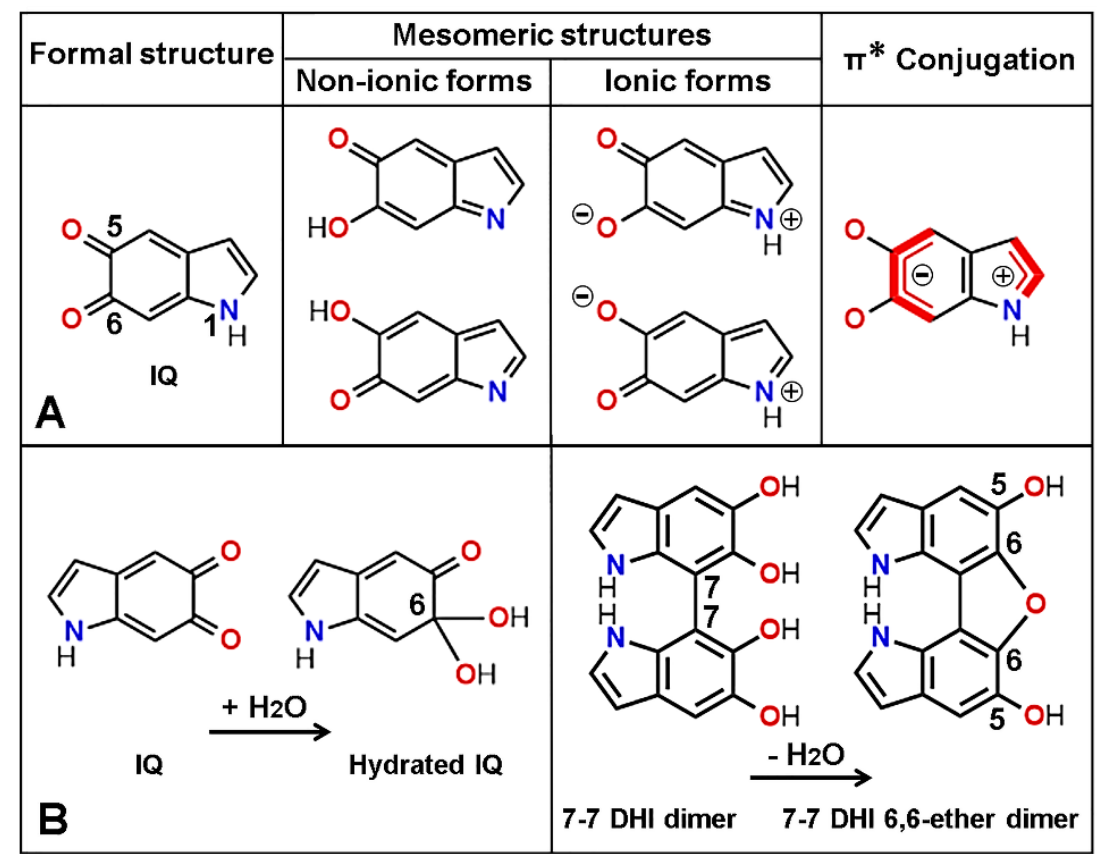

Figure 2. Chemical structures of melanin monomers drawn with ChemDraw Ultra v12.0 software. (A) Formal, mesomeric (non-ionic and ionic forms), and $\pi^{*}$-conjugated structure of indole-5,6quinone (IQ). In the later structure, red thick and thin lines represent the conjugated double bonds. (B) Formation of the 6-hydrated IQ (left), and the 6,6-ether product from the 7-7 dihydroxy-indole (DHI) dimer (right).

In the earliest formulation, Olivieri and Nicolaus [45] proposed the present BQPo model as a "porphyrin-like graphitic structure" for DHI-melanin. A planar, three-layer stacked model appeared in their work as Figure 4, which illustrated a polymer with ether bridges, causing a non-shown curvature. Therefore, the correct planar stacked model without ether bridges is here represented as Figure 3.

To substantiate chemical structures and processes, molecular modeling was performed following previous descriptions [32,33,47]. Inspection of molecular orbitals (MOs) of eumelanin models shows the conjugation changes induced by photo-excitation: ground and excited singlet states of molecules $\left(S_{0}\right.$ and $S_{1}$, respectively) result in different MOs. The highest-occupied (HOMO), and lowest-unoccupied (LUMO) MOs represent the energy levels of the ground and excited molecule, respectively [18]. In HOMO-d and LUMO+d, $d$ is from 0 to the maximum energy level, and the HOMO-LUMO separation corresponds to the forbidden Fermi's energy gap (Eg) between the valence band (VB) and conduction band (CB) of semiconductors. The orbital phases are denoted by colors or signs of $\pi$ - orbital lobes. Fused lobes with the same color or sign are in-phase, and those with isolated (unfused) 
lobes with different colors or signs are out-of-phase. In MO images, positive and negative signs have nothing to do with charge. In the case of the planar tetra-BQPo model (Figure 4), the LUMO+0 pattern shows a clear longitudinal orientation, whereas HOMO-0 has rather transversal components.

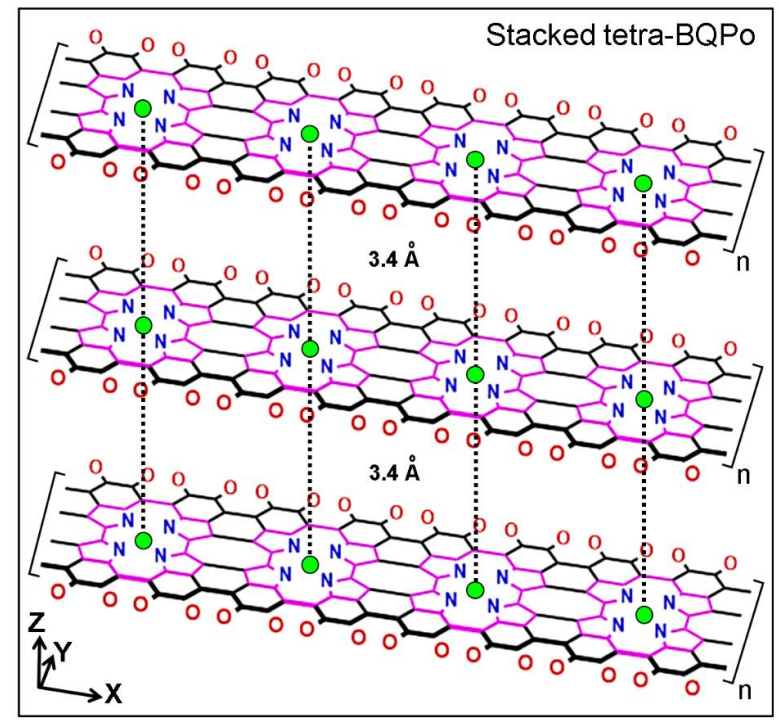

Figure 3. Schematic representation of the modified 3-layer "porphyrin-like graphitic structure" from Olivieri and Nicolaus [45], which corresponds to the poly-BQPo model with quinone or catechol instead ether bridges, a planar structure, and interlayer spacing of $3.4 \AA$. On account of the redox equilibrium and mobility of $\mathrm{H}$ atoms, $\pi$ bonds and $\mathrm{H}$ are omitted, and only skeletal $\sigma$ bonds are shown. Small green circles in the center of porphycene rings (violet) represent possible metal cations. $X, Y$, and $Z$ axes are indicated. The figure was obtained using the ChemDraw Ultra v12.0 software.
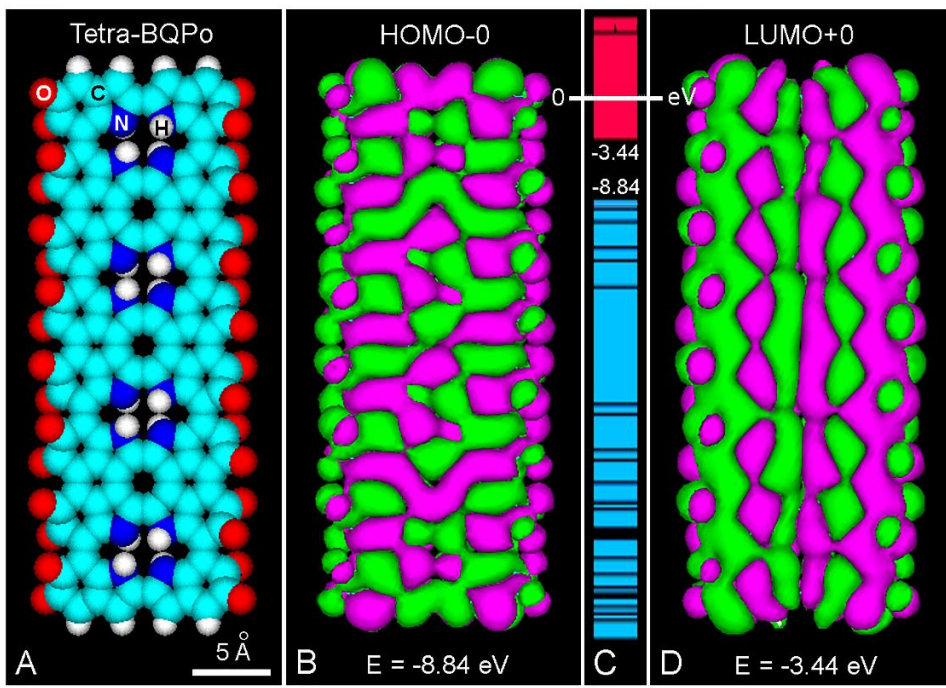

Figure 4. BQPo model. (A) Frontal view of an atomic volume model of the planar tetra-BQPo (HyperChem v7, MM+ energy minimization: $0.1 \mathrm{kcal} /(\AA \mathrm{mol})$ ). (B,D) Comparison between HOMO0 and LUMO+0 patterns (HyperChem 7, PM3 geometry optimization as in (A), Gouraud shaded 3D isosurface, orbital contour: 0.00035), showing positive (green) and negative (violet) $\pi$-orbital lobes with energy E values. Observe the long LUMO+0 lobes that correspond to the conjugated double bond pattern. (C) Gallery of energy levels and the HOMO-0/LUMO+0 energy gap (Eg = $5.4 \mathrm{eV})$ from $-8.84 \mathrm{eV}$ to $-3.44 \mathrm{eV}$, respectively, showing the massive occurrence of LUMO states $(\mathrm{CB}$, red) and HOMO states (VB, blue) (Reproduced from the Open Access reference [33]). 
Quinone compounds containing the vicinal carbonyls $(=\mathrm{HC}-\mathrm{CO}-\mathrm{CO}-\mathrm{CH}=)$ from benzoquinones (eumelanin, allomelanin) show a longitudinal LUMOs pattern. In these graphitic materials (melanins, carbon pigments), the massive dissipation of the electronic energy from excited MOs as vibrational energy produces a great amount of heat, namely, a photothermal response [32]. The increase in absorption and dark color of DHI-melanin by further oxidation is explained by the conversion of catechols to quinones [52]. It seems logical to assume that, in pigments with increased number of linear benzoquinones, black color and broad-band absorption spectra are closely related to the high $\pi^{*}$-conjugation and extended longitudinal LUMO components, with a reduction in the Eg and an increase in semi-conductivity.

MOs of some linear eumelanin models have been described in previous reviews $[32,33]$. Regarding the BQPo model (Figure 5A), the formation of ether bridges [45] leads to a chain curvature and potential spiral organization of the poly-BQPoe model [33]. In this case, the excited state LUMO+1 of dodeca-BQPoe (Figure 5B) shows an extended longitudinal $\pi^{*}$-electron conjugation, as well as fused MOs, whereas the ground HOMO-0 has a transversal conjugation (not shown). The energy levels of HOMO and LUMO states (Figure 5C) appear again as compact "semiconductor-like" VB and CB, respectively.

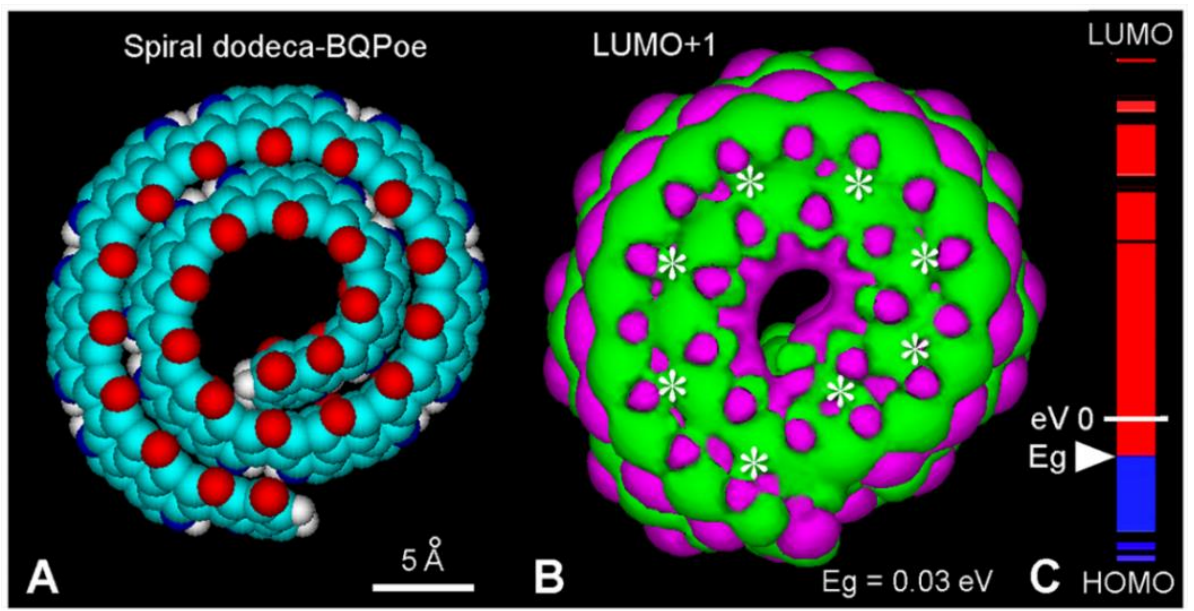

Figure 5. Spiral BQPoe model of eumelanin. (A) Lateral view (atomic volume) of a spiral dodecaBQPoe with two complete spires (MM+ method, converged to $1 \mathrm{kcal} /(\AA \mathrm{mol})$ ). For element colors see Figure 4. (B) LUMO+1 of dodeca-BQPoe, showing the spiral fused pattern (asterisks). Extended Hückel method [58], Gouraud 3D isosurface, contour value: 0.0001. (C) Energy levels of dodecaBQPoe, showing the small energy gap $(\mathrm{Eg}$, white triangle $=0.03 \mathrm{eV})$, from HOMO-0 $(-9.88 \mathrm{eV})$ to LUMO+0 (-9.85 eV), and the massive occurrence of LUMO (CB, red) and HOMO (VB, blue) states $(\mathrm{B}, \mathrm{C})$ reproduced from the Open Access reference [33].

From the morphological point of view, transmission electron microscopy (TEM) studies of natural and synthetic eumelanin reveal stacked planar electron-dense sheets, which is characteristic of a graphitic organization. Graphite-like soft curved or marked wavy layers, as well as concentric onion-like structures, are also seen in eumelanins observed by TEM (Figure 6) in all cases with a $\sim 3.4 \AA$-interlayer separation, which is also confirmed by X-ray diffraction analysis [26,59-62].

On the other hand, it is known that carbon black nano- and micro-particles have onionlike structures formed by concentrically arranged graphene sheets. Examples are closedcage fullerenes spheres $[63,64]$, onion-like graphitic spheres [65], nautilus-like fullerene spirals [66,67], and graphene nano-scrolls structured as Archimedean spirals [68-72]. The occurrence of spiral fullerenes and graphenes support the possibility that an oligo- or poly-BQPoe chain could also grow as spiral structures [33]. To this respect, the similarity between both BQPoe and graphene spirals and scrolling processes is astonishing (compare Figure 5A (this work) and Figure 1 from [70]). 


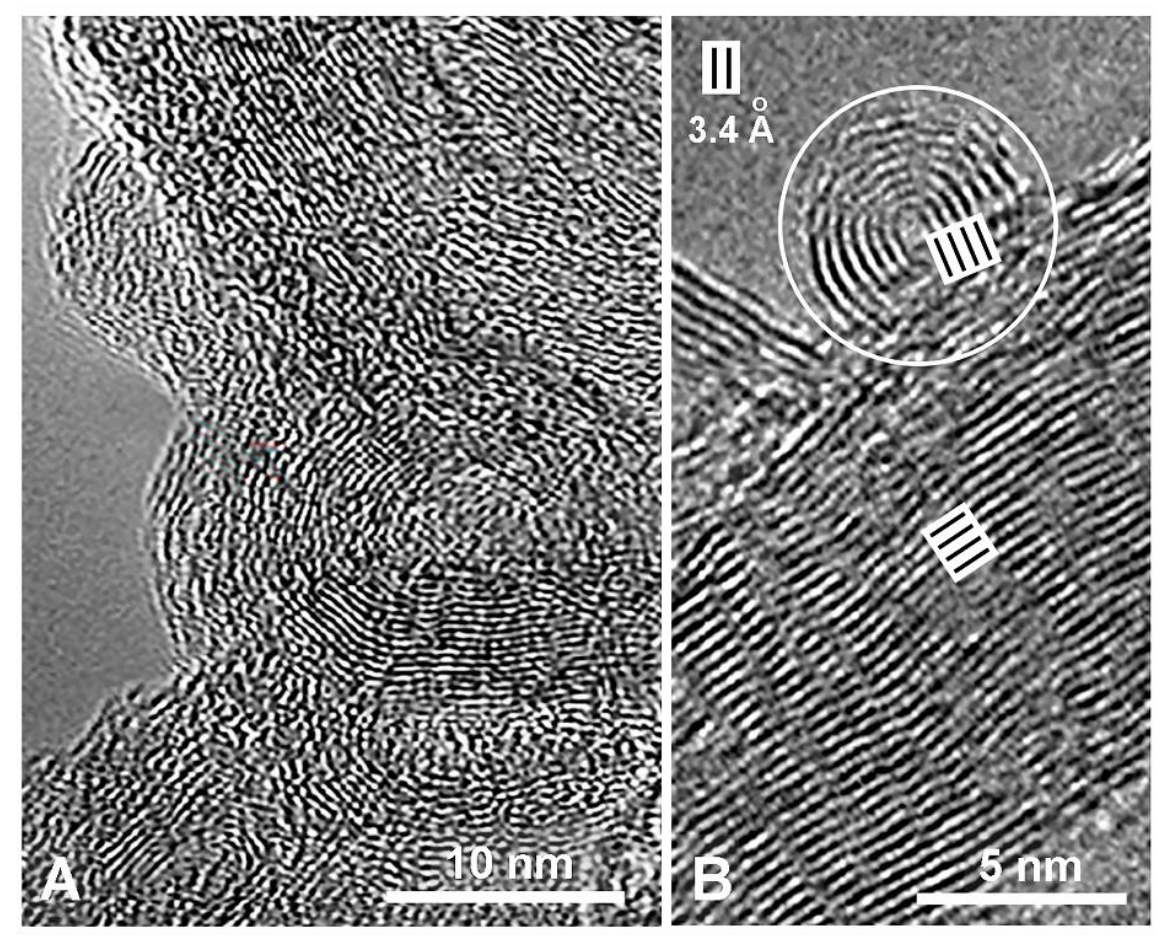

Figure 6. Typical TEM micrographs of eumelanin. (A) Synthetic eumelanin (PDA) produced from the oxidation of dopamine, showing the graphitic organization of molecular aggregates that form stacked wavy nanostructures. (B) High-resolution TEM image of the same material, showing an onion-like nanobody composed of stacked layers arranged in concentric rings, as well as planar and wavy graphite-like eumelanin sheets. Interlayer spaces of $3.4 \AA$ are indicated (adapted from [62] with copyright permission).

It is most exciting to consider that the circular or spiral organization of sp2 carbon sheets [64] might also occur in eumelanin protomolecules (e.g., BQPoe model; see Figure 5). A supramolecular organization of spiral melanin units could be formed by aggregation of smaller and then larger globular structures [73,74]. Spherical onion-like proto-particles (20-50 $\AA$ ) can be arranged by about four turns $(\sim 42 \AA)$ of the Archimedean-type spiral BQPoe model [33], and then they could aggregate into larger globular bodies following co-axial and / or side-to-side parallel linkages. It has been proposed that the supramolecular structure of natural and synthetic eumelanins could derive from a fractal organization of globular units involving different hydration levels, with low $\mathrm{pHs}$ and high ionic strength promoting aggregation to larger structures [27,51], in agreement with the hypothesis that small (proto) particles are capable of aggregating to build the final eumelanin structure [75].

The proposed stacked planar BQPo and spiral BQPoe models agree with most structural views of melanins $[46,60,76,77]$. In the local-order-global-disorder model, ordered nanostructured proto-particles grow first, then aggregate to form disordered spherical particles, that self-arrange again to form large globular structures [78]. Eumelanin was claimed to be composed of onion-like concentric circles [26], which agrees with the idea that the eumelanin proto-molecules could assume fullerene-like closed forms $[45,46]$, or spiral globular structures [33].

\section{Spectroscopy and Fluorescence of Melanins}

As in the case of graphite and graphene materials, melanins show a broad-band photonic absorption with exponential decay from the ultraviolet (UV) to visible and nearinfrared (NIR) region $[28,32,79]$. It is accepted that this spectrum fits better to graphitic materials and inorganic semiconductors with $\mathrm{VB}$ and $\mathrm{CB}$ (and small Eg, $\sim 0.5-1.5 \mathrm{eV}$ ) [31,80] than to small organic chromophores with structured absorption peaks typically related to $\pi$-bonding and $\pi^{*}$-antibonding localized orbitals. The conjugated structure of eumelanins 
also allows easy redox changes and reversible equilibrium between quinone and catechol groups. Another unusual and intriguing feature of eumelanin is its striking binding capacity to a large number of inorganic cations, colorants, and drugs, a topic which will be discussed in the next Section.

Although highly compacted eumelanin is a very dark or even black material, the microscopic color of melanosomes in unstained skin sections is pale brown (Figure 7A,C), which can slightly modify the color of the pigment in subsequently stained sections. Eumelanin is capable of dissipating $>99.9 \%$ of absorbed UV-visible radiation through a non-radiative decay mode [81]. Since the radiative decay of eumelanin is nearly zero, it is expected that its fluorescence emission should be negligible. In fact, melanosomes from unstained paraffin skin sections show no fluorescence at all under UV, blue, or green excitation (Figure 7B). Easy visualization of melanosomes in melanoma cell cultures can be achieved using phase contrast optics (Figure 7C).

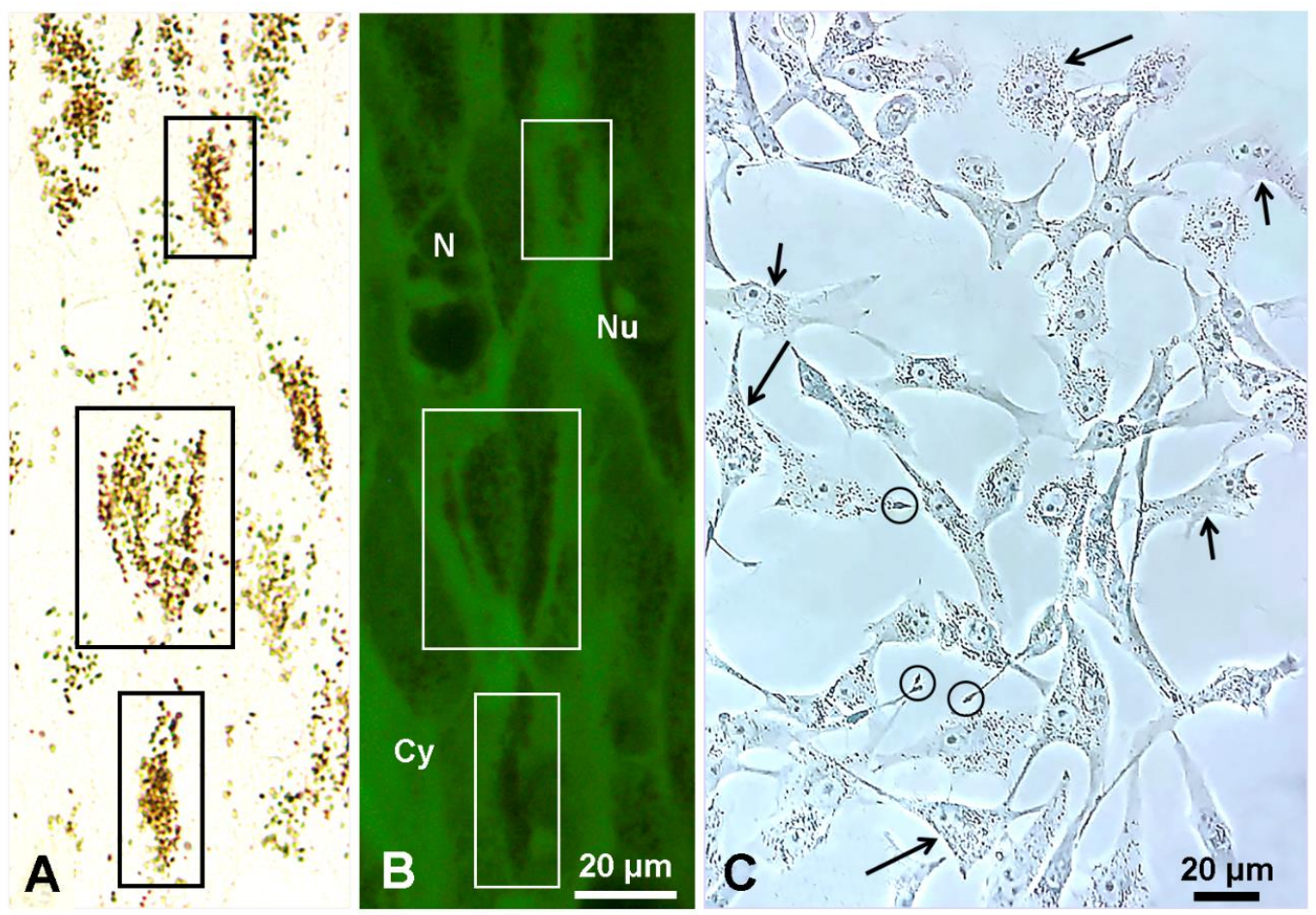

Figure 7. Melanosomes from paraffin sections and melanoma cell cultures. (A) Bright-field image of a formaldehyde-fixed, paraffin-embedded skin section of Eubalaena australis showing the brown color of unstained (control) melanosomes. Regarding melanin, the epidermis of this whale is an excellent tissue model due to the great abundance of clearly identifiable melanosomes within keratinocytes [82].

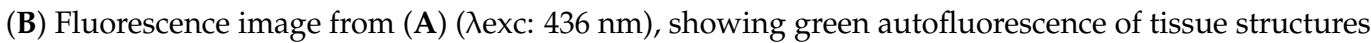
( $\mathrm{Nu}$ : nucleoli, N: nuclei, $\mathrm{Cy}$ : cytoplasm) and no emission at all from melanosomes. Rectangles show defined areas with melanosomes and correspondence between (A,B) images (courtesy of M.C. Carou). (C) Cultured OL melanotic cell line, grown in complete DMEM medium, from an oral canine melanoma (kindly provided by L.M.E. Finocchiaro and G.C. Glikin), and observed by phase contrast. Observe living cells with numerous and scarce brown melanosomes in the cytoplasm (large and small arrows, respectively), nucleoli within nuclei, and melanin-containing dense endings of cytoplasm prolongations (encircled) (Courtesy of S.A. Moreno).

The reported yellow autofluorescence of natural and synthetic eumelanin, neuromelanin, and pheomelanin ( $\lambda$ exc: $\sim 470 \mathrm{~nm}, \lambda \mathrm{em}: \sim 540 \mathrm{~nm}$ ) seems to be caused by degradation products induced by $\mathrm{H}_{2} \mathrm{O}_{2}$ oxidation and/or UV/violet irradiation [83-85]. In keeping with this, fluorescent quantification of melanin can be made after oxidative degradation [86]. The fluorescence of opio-melanins is also due to low- and middle-molecular weight fractions 
formed during oxidative photo-bleaching [87]. In ophthalmoscopy, where the lifetime of autofluorescence from the retinal pigment epithelium (RPE) is recorded, the most relevant emission is not due to melanin but to lipofuscin, NAD $(\mathrm{P}) \mathrm{H}, \mathrm{FAD}$, collagen, elastin, and carotenoids [88]. The lipofuscin A2E is a relevant fluorophore of the RPE [89]. Under $785 \mathrm{~nm}$ near-infrared (NIR) excitation, eumelanin shows a very weak broad-band emission between 820 and $920 \mathrm{~nm}$, which appears superimposed with the Raman scatter at 880 and $890 \mathrm{~nm}$ [90], possibly contributing to the NIR autofluorescence in ophthalmoscopy. Interestingly, a non-invasive recording of Raman spectra has been proposed for the quantification of eu- and pheomelanin [91].

On the other hand, formaldehyde-induced fluorescence (FIF) in melanocytes was identified as due to the reaction of the aldehyde with DOPA, yielding an isoquinoline derivative [92-94]. A green FIF was also observed in pheomelanin-containing cells that arises from 5-S-cysteinyl-DOPA rather than DOPA, allowing for the detection of melanoma metastasis by serum and urine analysis [95].

In contrast, fluorescence quenching by melanin can reduce the background autofluorescence of cells subjected to incorporation of fluorescence-labeled mRNA probes [96]. Likewise, on account of the broad-band absorption, fluorescence quenching by graphene oxide has been proposed for removing the signal of free single-stranded fluorescent DNA nanoprobes (attached to the graphene surface), whereas those hybridized as DNA duplexes remain far away of the surface and retain the fluorescence signal [97]. Interestingly, in spite of its broad-band absorption, which could quench emission by an inner filter or screen effect, melanin allows the emission of bound fluorophores in microscopic preparations, appearing highly fluorescent after appropriate labeling, a feature that will be described later.

\section{Staining Mechanisms of Melanin}

Eumelanin is the melanin type mainly stained or labeled in melanosomes, but studies on the staining of pheomelanin or allomelanin seem rather overlooked. Although eumelanin is a dark pigment, light microscopic visualization depends on its concentration in the melanosome. It must be noted that cultured melanomas often show weakly or non-pigmented cells. The well-known B16 melanoma line can differ significantly in pigmentation, as well as the expression of antigens, growth rate in mice, metastatic potential, etc. [39]. In contrast, the canine OL melanoma cells show conspicuous melanosomes (see Figure 7C). Microscopic analysis of cultured cells should allow the observation of melanosomes [98] using appropriate optics, but unfortunately detailed morphological studies are often not performed, or the absence of melanosomes is subtlety dismissed.

Several immunohistochemical methods regarding melanoma diagnosis and prognosis are available [99], but the classical silver staining by the Fontana-Masson (FM) method for melanin remains useful [100]. In this argentaffin reaction, which does not require any developer, the silver diammine cation $\left(\mathrm{Ag}\left[\mathrm{NH}_{3}\right]_{2}\right)^{+}$from an ammoniacal silver nitrate solution is reduced by melanin to a dark colloidal metallic $\mathrm{Ag}^{0}$, but chromaffin cells and lipofuscin pigments are also revealed by this method. In addition to FM, Warthin-Starry (WS) silver stain is also used to reveal melanin [101,102]. In the WS stain, hydroquinone is added to the silver solution, increasing the sensitivity and specificity of detection, possibly by pre-reduction in melanin or by reducing the silver bound to melanin [102].

Most staining reactions are based on the affinity of eumelanin for cationic compounds and dyes (basophilia). Eumelanin is negatively charged at $\mathrm{pH}$ values above 4 [103], and then some staining reactivity can be related to its polyanionic nature. Melanin reacts with metal cations, and can be stained by metal-dye complexes (e.g., aluminum-hematein), and cationic colorants. Reactivity of catechols and quinones seems to be also responsible for strong adhesive binding to particles and surfaces [27,104-106].

Taking into account most of the reports on binding of inorganic cations to melanin, the following alkali, alkali earth, and transition metals can be mentioned: $\mathrm{Na}, \mathrm{Mg}, \mathrm{Al}, \mathrm{K}$, $\mathrm{Ca}, \mathrm{Ti}, \mathrm{V}, \mathrm{Cr}, \mathrm{Mn}, \mathrm{Fe}, \mathrm{Co}, \mathrm{Cu}, \mathrm{Zn}, \mathrm{Sr}, \mathrm{Mo}, \mathrm{Ag}$, Cd, Sb, Hg, Pb, As, etc. [19,30,77,78,107-110]. Although native sepiomelanin appears as a $\mathrm{Ca}$ and $\mathrm{Mg}$ salt, exchange reactions with the 
above-mentioned cations are possible. The amount and binding affinity of melanin for some metals can be very large, binding to $\mathrm{Ca}^{2+}, \mathrm{Mg}^{2+}, \mathrm{Sr}^{2+}$, and $\mathrm{Cu}^{2+}$ being 4, 5, 14, and 34 times stronger than EDTA, respectively. For $\mathrm{Ca}, \mathrm{Mg}, \mathrm{Fe}, \mathrm{Cu}$ o $\mathrm{Zn}$, the saturation levels of binding are $\sim 3-4$ indole units per ion [79]. Binding for metal ions is about $6 \times 10^{20}$ sites per gram of dried melanin [107].

Diagnostic and microscopic applications of metal binding to melanin are abundant. Melanoma detection by magnetic resonance imaging (MRI) could be improved by using melanin uptake of ${ }^{67} \mathrm{Ga}$ and ${ }^{111} \mathrm{In}$ [111]. Doping of eumelanin and synthetic melanin with titania $\left(\mathrm{TiO}_{2}\right)$ nanoparticles, and $\mathrm{Fe}^{3+}$ or $\mathrm{Gd}^{3+}$ metal ions with catechol or quinone units (Figure 8), produces nanoplatforms for multimodal imaging and therapeutic applications, enhancing light absorption, photocatalysis, and photothermal effect [30,78,108-110].
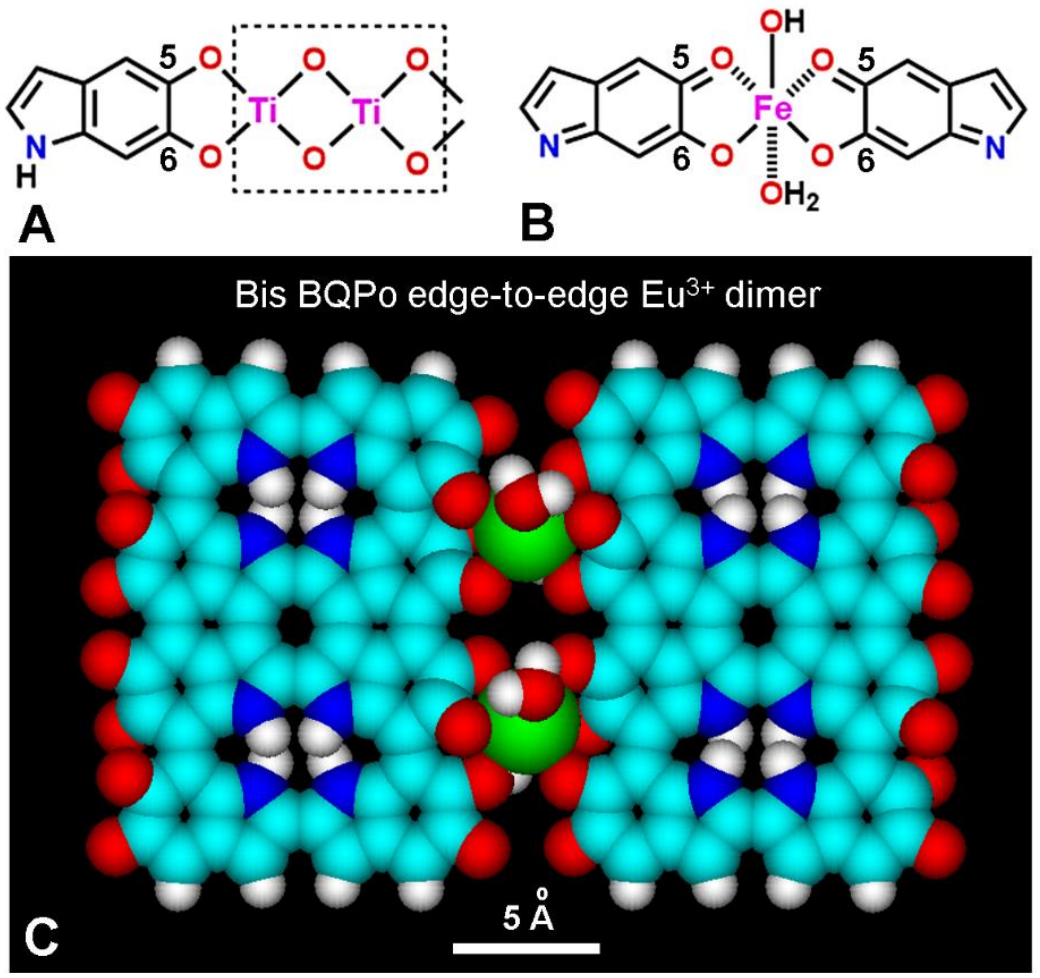

Figure 8. Interaction of melanin IQ units with metals. (A,B) Complexes with $\mathrm{TiO}_{2}(\mathbf{A})[30,109]$, and $\mathrm{Fe}(\mathrm{B})$ [78], showing the geometry of chelating $\mathrm{O} 5$ and $\mathrm{O} 6$ atoms. Observe that $\mathrm{Ti}^{4+}$ belongs to a nanoparticle of $\mathrm{TiO}_{2}$ (dashed rectangle). Axial O ligands $\left(\mathrm{HO}^{-}, \mathrm{H}_{2} \mathrm{O}\right)$ complete the hexa-coordination of $\mathrm{Fe}^{3+}$. (C) Frontal atomic volume view of two bis-BQPo units bound through two edge-to-edge bridges of hexa-coordinated $\mathrm{Eu}^{3+}$ ions (green, with two additional $\mathrm{H}_{2} \mathrm{O}$ ligands to complete the octa-coordinated arrangement). HyperChem v7 software was used, with $\mathrm{MM}+$ energy minimization converged to $\mathrm{E}=0.1 \mathrm{kcal} /(\AA \mathrm{mol})$. For element colors see Figure 4.

In the case of $\mathrm{TiO}_{2}$, the $\mathrm{O}$ atoms of IQ ligands forms a charge-transfer complex, which also promotes polymerization of the monomer [109] (Figure 8A). The iron uptake reaction gives a blue-green color [100], which is typical of ferric-catechol complexes [7,78]. $\mathrm{Fe}^{3+}$ hexa-coordinated by $\mathrm{O}$ atoms from catechol, forms a mononuclear complex with typical square-planar geometry and octahedral arrangement [78] (Figure 8B). Likewise, borate esters with tetrahedral geometry of anionic boron may be formed using the $\mathrm{O} 5$ and $\mathrm{O} 6$ catechol atoms of DHI. Strong melanin binding of trivalent lanthanides ( $\mathrm{La}, \mathrm{Pr}, \mathrm{Nd}, \mathrm{Sm}, \mathrm{Gd}$, Dy, Ho, Er, Tm) with the O ligands of IQ has been also reported [107,108]. Using molecular docking of cations on the melanin BQPo model, binding of $\mathrm{Ca}^{2+}$ and lanthanides $\left(\mathrm{Eu}^{3+}\right.$, $\mathrm{Dy}^{3+}$ ) to $\mathrm{O} 5$ and $\mathrm{O} 6$ have been found (Figure 8C).

Interestingly, the luminescence of $\mathrm{Eu}^{3+}$ under $\mathrm{UV}$ excitation [18] and its binding to melanin (Figure 9) can be microscopically visualized due to its red $(620 \mathrm{~nm})$ emission when 
complexed with IQ, which act as a ligand UV antenna for $\mathrm{Eu}^{3+}$ photoexcitation. Likewise, $\mathrm{Pr}, \mathrm{Nd}, \mathrm{Sm}, \mathrm{Dy}, \mathrm{Ho}$, and Er are NIR-emitting lanthanides that when bound to IQ units of melanin could induce selective tumor-damaging luminescent heating.

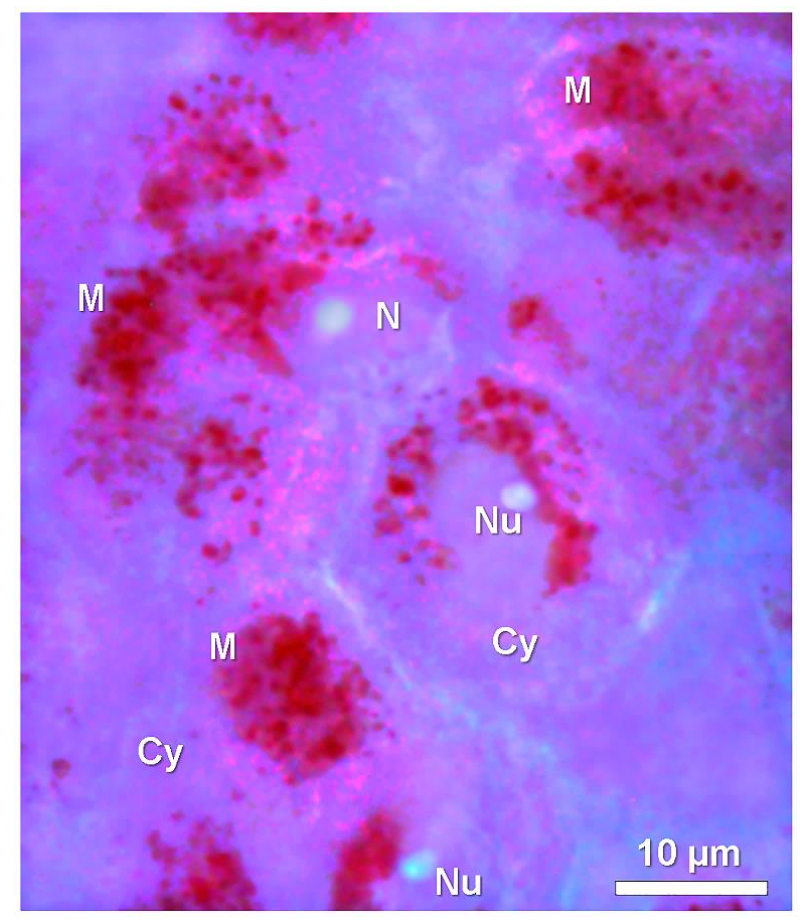

Figure 9. Luminescence of the lanthanide $\mathrm{Eu}^{3+}$ complexed with melanin. Formaldehyde-fixed, paraffin-embedded section of the skin of Eubalaena australis treated with europium acetate $(1 \mathrm{mg} / \mathrm{mL}$ for $1 \mathrm{~h}$, DPX mounting), showing the red luminescence $(620 \mathrm{~nm})$ of melanosomes $(\mathrm{M})$ within keratinocytes, and the blue autofluorescence of the cytoplasm $(\mathrm{Cy})$, and nucleoli $(\mathrm{Nu})$ within nuclei $(\mathrm{N})$. $\lambda$ exc: UV $(365 \mathrm{~nm})$.

After using the common nuclear staining of paraffin tissue sections by the cationic blue aluminum-hematein complex $(\mathrm{H})$, the pale brown color of melanosomes is shifted to blue-violet, which depends on the binding of $\mathrm{Al}$ ions of the complex to melanin anionic sites. When followed by eosin $\mathrm{Y}$ staining (H\&E), melanosomes are visualized in dark violet-brown or even black color (Figure 10). In addition to $\mathrm{H}$, other colored or fluorescent dye-metal lakes are expected to stain melanosomes.

Numerous cationic dyes can stain eumelanin $[7,33,100]$. Examples are methylene blue, toluidine blue, thionine, Nile blue, and acridine orange. The precise binding mechanism of cationic dyes to eumelanin has been rather overlooked. In contrast to classical views [100], melanosomes from both normal skin and melanoma cells give metachromatic staining and fluorescence when stained with thionine, toluidine blue, and acridine orange. A clear example is toluidine blue metachromatic staining of keratinocyte melanosomes in the skin of Eubalaena australis (Figure 11). 


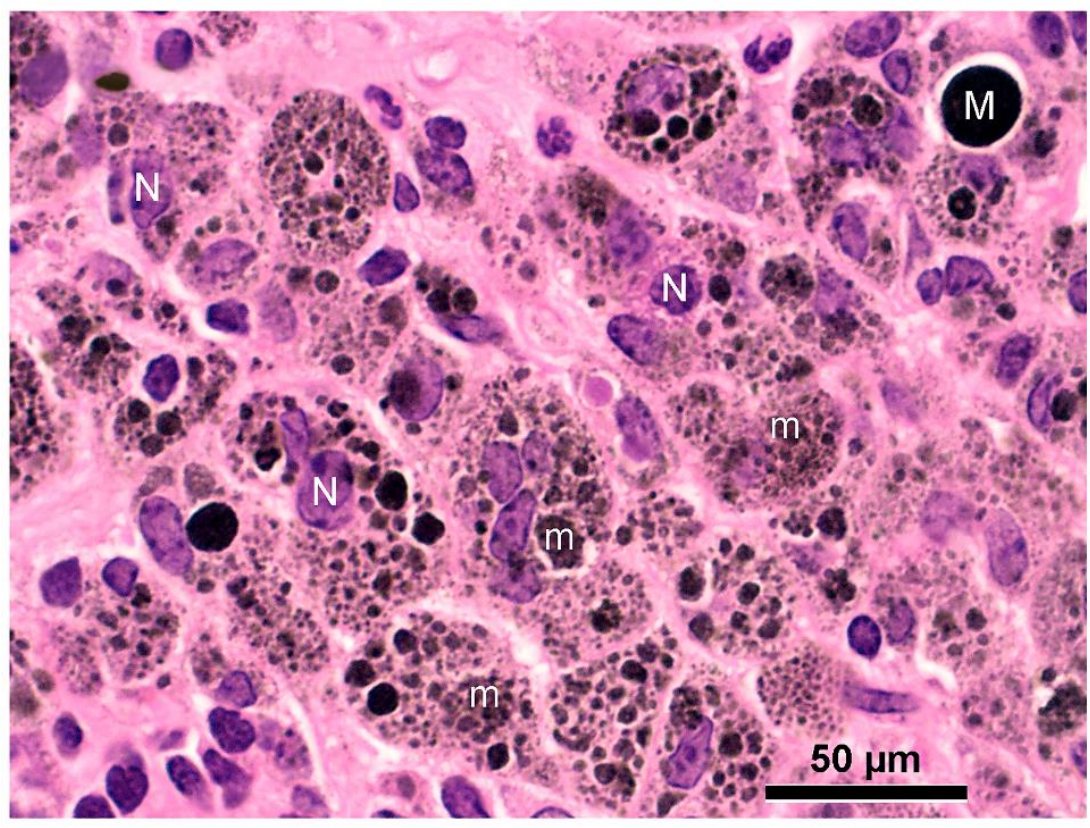

Figure 10. Bright-field hematoxylin and eosin (H\&E) image of a formaldehyde-fixed, paraffin section of the murine B16-F10 melanotic melanoma growing in a Balb/c mouse [112]. The tumor shows numerous intracellular melanosomes with different size and shape $(\mathrm{m})$, and large extracellular melanin granules $(\mathrm{M})$, both stained in dark brown-black color. In contrast with small and rather uniform melanosomes from normal skin, coarsely deformed melanosomes are often found in pigmented melanomas. This tumor sample had abundant and large melanosomes.

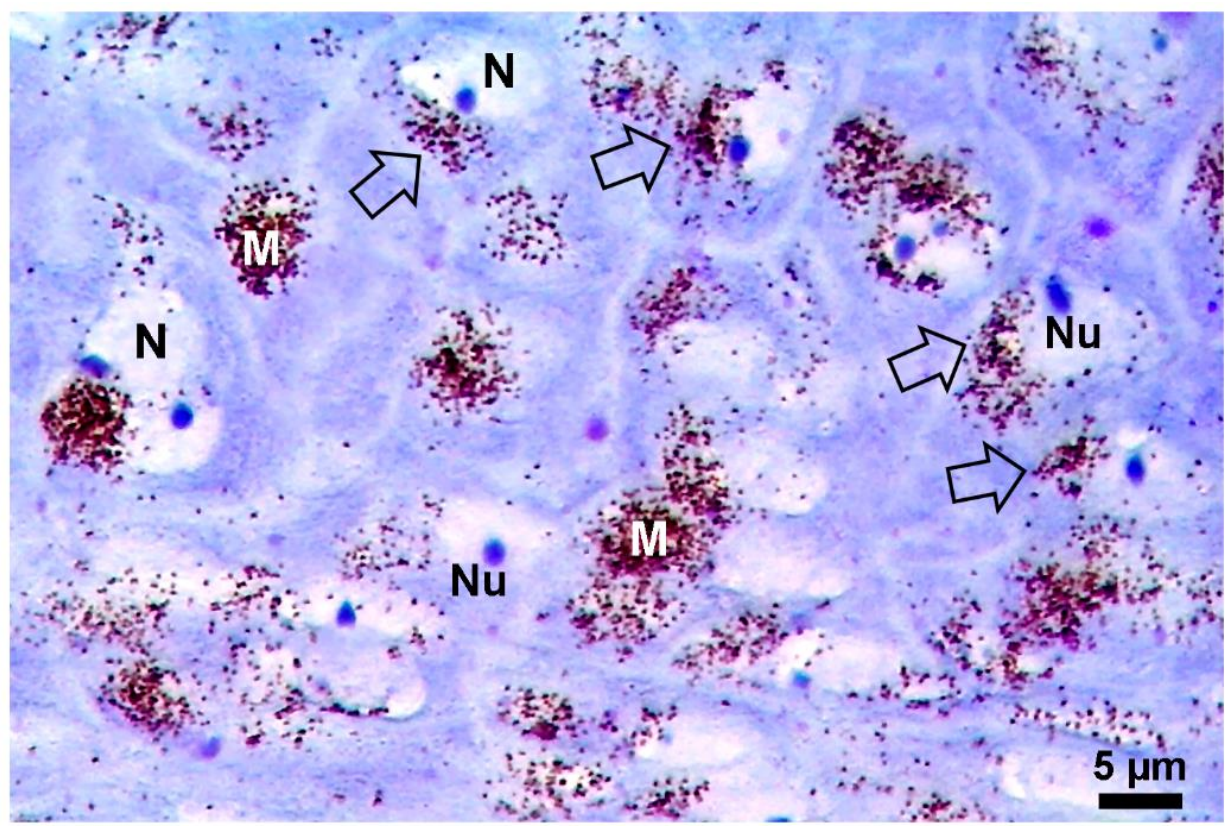

Figure 11. Paraffin section of the formaldehyde-fixed skin from a southern right whale (Eubalaena australis) stained with toluidine blue $(50 \mu \mathrm{g} / \mathrm{mL}$ for $10 \mathrm{~min}$, DPX mounting), showing the strong and selective metachromatic reaction of melanosomes (dark violet) within keratinocytes, and the orthochromatic reaction (blue) of basophilic cytoplasm and nucleoli $(\mathrm{Nu})$ within nuclei $(\mathrm{N})$. The same pattern is observed after thionine staining. UV-protective umbrellas (asymmetric arrangement) of melanosomes with supra-nuclear localization [113] are indicated (arrows) (Reproduced from the Open Access reference [33]). 
The polyanionic character of melanin could explain its metachromatic staining reaction with appropriate colorants. In the case of double-stranded nucleic acids, intercalation between base pairs is favored when compared with external electrostatic binding to phosphate sites $[18,114]$. The same preference seems to occur for melanin when the graphitic BQPo model is analyzed for dye docking using molecular modeling: cationic acridine and thiazine colorants prefer face-to-face hydrophobic binding (lower free energy) instead of edge-to-edge ionic interactions (higher free energy).

It is well known that planar aromatic compounds can intercalate into host lattices forming inclusion complexes [115]. In the case of tissue components such as polysaccharides, lignin, nucleic acids duplexes, etc., bathochromic changes in the absorption spectra are induced by monomerization of colorants, which remain trapped between aliphatic chains or aromatic rings of the biopolymer [116,117].

Since Lerman's formulation of the intercalative binding mode into DNA [118], numerous colorants have been found to bind to nucleic acid duplexes by intercalation [114,119], using strong face-to-face hydrophobic and $\pi-\pi$ electron interactions between planar dyes and base pairs. Therefore, on account of the aromatic character of eumelanin, intercalation of planar cationic dyes should be the preferential binding mode, as occurs with nucleic acid duplexes stained by acridine, thiazine, azine, oxazine, and xanthene dyes. A gallery of representative cationic colorants and fluorochromes involved in melanin binding is presented in Figure 12.

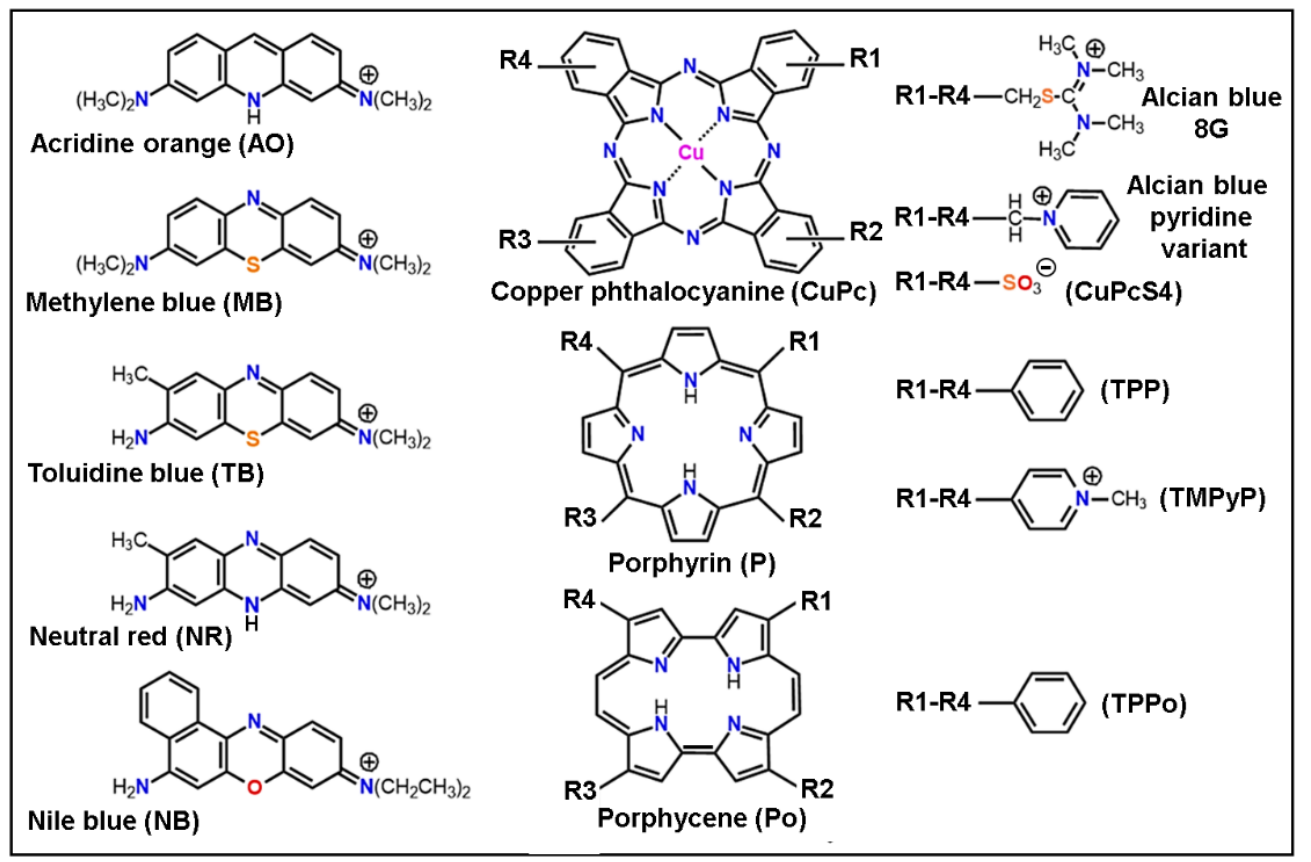

Figure 12. Chemical structure of some lysosome probes and potential eumelanin-binding colorants, belonging to different chemical groups, drawn using the ChemDraw Ultra v12.0 software. Abbreviated names of probes and dyes are indicated in parentheses.

Stacked dye aggregates commonly found in classical tissue histochemistry give metachromatic reactions, which are most apparent for toluidine blue $[120,121]$, and acridine orange $[18,122]$. They have the advantage that ortho- and metachromatic peaks (and colors) are well defined and spectrally separated.

In this respect, the copper-phthalocyanine $(\mathrm{CuPc})$ macrocycle is an intriguing model dye regarding binding to eumelanin. A tetrasulfonated $\mathrm{CuPcS} 4$ dye deposited on multiwall carbon nanotubes has been used as electronic conductor in photovoltaics [123]. The cationic derivative Alcian blue pyridine variant (ABPV) was also applied in TEM studies of PDAmelanin [62]. No increase in electron contrast over that of a graphitic structure was apparent, 
but a new composite was formed by layer-by-layer film deposition of PDA-melanin and ABPV, which displayed an electrical conductivity five orders of magnitude higher than that of pure melanin films [62].

Interestingly, clear $610 \mathrm{~nm}$ metachromatic spectra (peak/shoulder: 610/670 nm) appear after addition of successive monomeric ABPV-PDA layers [62]. This is an intriguing finding, because dye intercalation involves binding of isolated monomers, canonically leading to an orthochromatic reaction (red or bathochromic spectral shift), and not to metachromasia (hypsochromic shift). Spectroscopic analysis confirms that in the presence of Sepia melanin (SM), the absorption peak of the AB-SM complex remains metachromatic (blue), as it would correspond to a highly aggregated state and not to the intercalated monomers (Figure 13). This unexpected metachromatic reaction can be explained on account of the massive occurrence of overlapping LUMOs in the AB/SM intercalated complex, allowing the $\pi^{*}$-electron coupling between all $\mathrm{CuPc}$ chromophores [33]. Thus, long-range $\mathrm{CuPc}$ "aggregates" are established from $\mathrm{CuPc}$ intercalated monomers.

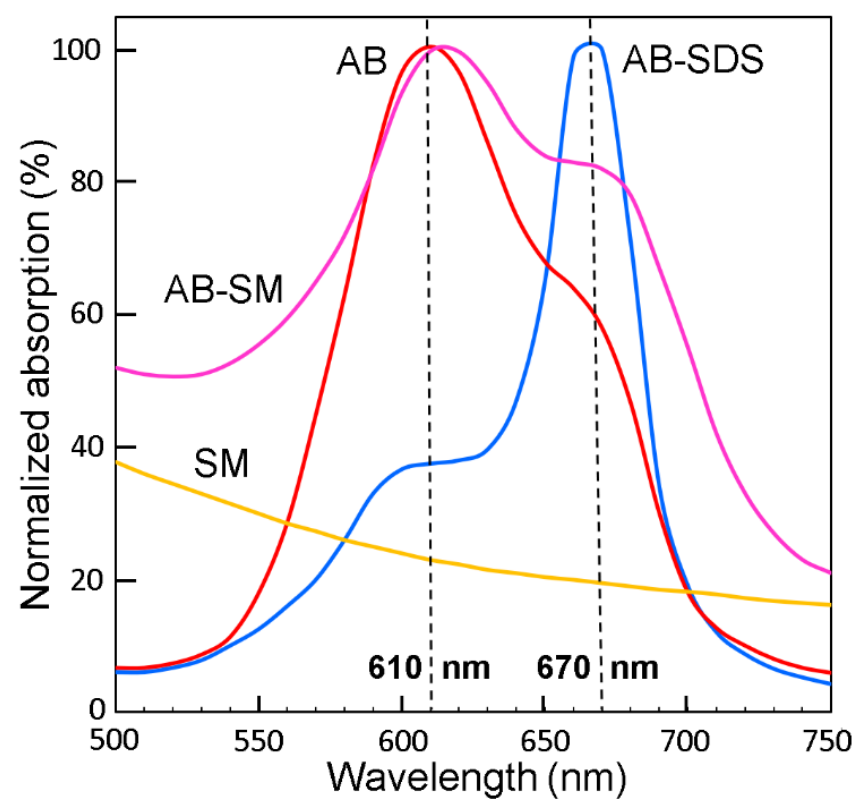

Figure 13. Absorption spectra of Alcian blue $8 \mathrm{G}(\mathrm{AB})$. The dye was dissolved in distilled water $(\mathrm{AB})$, in $5 \%$ sodium dodecylsulfate (AB-SDS), and in commercial Sepia melanin (diluted 1:2000, $v / v$ in distilled water) (AB-SM). Note the position of metachromatic and orthochromatic peaks of AB at $\sim 610$ and $\sim 670 \mathrm{~nm}$, respectively. Part of the exponential absorption decrease in Sepia melanin as a typical broad-band graphitic material [32] is also shown (SM, normalized at $300 \mathrm{~nm}$ with the remaining dye peaks).

Positive charges (a) on the ring of phthalocyanine colorants (e.g., cuprolinic blue and its analogous zinc complex [124-126]), or (b) on the side chains (e.g., AB [127,128], and Alcian blue pyridine variant [129]) could be advantageous but not essential for intercalative binding and staining of eumelanin. Although there are no structural details of the dye binding to this substrate, it is logical to assume that, as it occurs in the face-to-face CuPc binding to the graphitic surface of carbon nanotubes [123], the same mechanism could also be possible for eumelanin.

\section{Lysosome and Melanosome Labeling}

Selective labeling of lysosomes and endocytic cell compartments (endocytosis vesicles, endosomes, phagosomes, trans-Golgi network, lysosome remnants such as age pigments or lipofuscin granules) is a well-known process. The main vital probes are acridine orange, acridine yellow, alizarin, auramine $\mathrm{O}$, 3,4-benzpyrene, Bismarck brown, brilliant cresyl blue, coupled azo dyes, eosin Y, erythrosin B, euchrysine 3R, Evans blue, FITC-dextran, fluores- 
cein, hematein and hematoxylin, hydroethidine, inorganic nanoparticles, Lucifer yellow $\mathrm{CH}$, methylene blue, neocyanine, neutral red, Nile blue, phloxine B, phosphine, primulin, proflavine, purpurin, quinacrine, thionine, toluidine blue, trypan blue, etc. [5,18,130-139]. Numerous lysosome probes are also efficient photosensitizers for photodynamic therapy (PDT) [140,141].

On the other hand, eosinophil, basophil, and azurophil leucocyte granules, sperm cell acrosomes, secretion (zymogen) granules, and particularly melanosomes, are acidic compartments that also have a clear lysosome lineage [18,35,36,142-144]. The intramelanosomal $\mathrm{pH}$ range is as low as 3-5, and the organelle contains proton-translocating ATPase, hydrolases, cathepsines B and L, and acid phosphatase [35]. In addition to colorants and fluorescent probes, an interesting feature is the high number of xenobiotics (nanoparticles, colloids, latex microparticles, metals, drugs) that can be up taken by lysosomes and melanosomes $[35,130]$.

Selective lysosome labeling with vital colorants and fluorochromes show metachromatic color, although toluidine blue (TB) and methylene blue (MB) give violet and blue colors, respectively; both dyes are just metachromatic, but the shift is only appreciated for $\mathrm{TB}$, because the shift for MB takes place entirely within the blue spectral region, and it is not appreciated by the eye. In the case of $\mathrm{CuPc}$, the colorant shows a spectral metachromasia in spite of the monomeric binding in PDA-ABPV films [62]. After acridine orange (AO) labeling, bright orange emission is observed in lysosomes from live cells, which is due to the low lysosomal $\mathrm{pH}$ and the aggregation of $\mathrm{AO}^{+}$, reaching local metachromatic concentrations (Figure 14A), whereas a weaker $\mathrm{AO}^{+}$accumulation produces a green orthochromatic emission in nucleoli, chromatin and cytoplasm [18]. Selective lysosome labeling by other photosensitizing dyes such the porphyrin ZnTPP, and the porphycene TPPo are shown in Figure 14B,C, respectively.
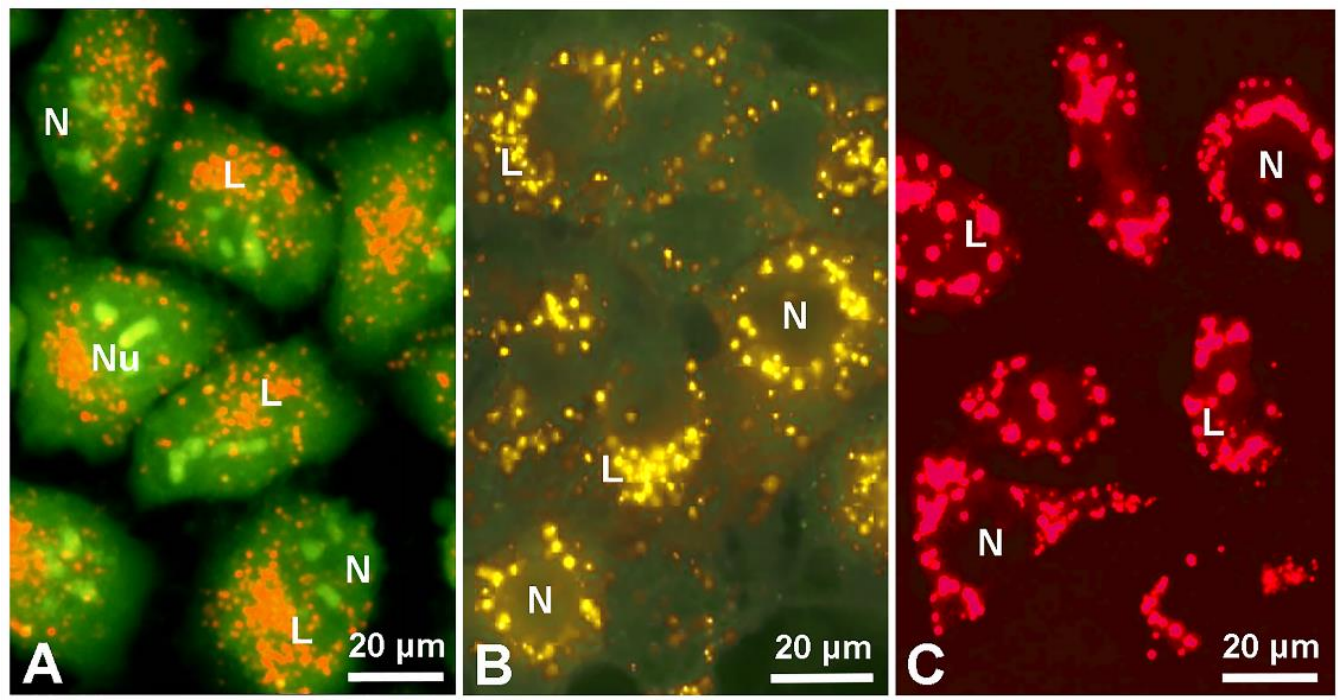

Figure 14. Fluorescence labeling of lysosomes (L). Nuclei $(\mathrm{N})$ and nucleoli $(\mathrm{Nu})$ are also indicated. All semi-confluent cell cultures were grown in complete DMEM medium. (A) A-549 cells labeled

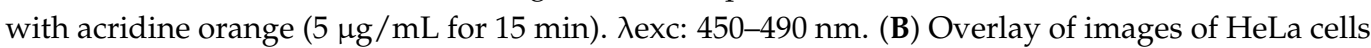
treated with ZnTPP [145] (10 $\mu \mathrm{M}$ in DPPC liposomes for $6 \mathrm{~h}$ (red signal), and then labeled with

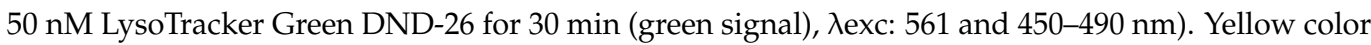
indicates colocalization in lysosomes. (C) HeLa cells labeled with the porphycene probe TPPo $(5 \mu \mathrm{M}$ in DPPC liposomes for $18 \mathrm{~h}$, $\lambda$ exc: $405 \mathrm{~nm}$ ). Observe the massive occurrence of large lysosomes after the prolonged TPPo incubation. After labeling, cell cultures were washed and mounted in PBS, and immediately observed.

Lysosomal photosensitizers such as AlPc2, AlPc4, CF3, Pc13, PoD, Py3 MeO-TBPo, SnEt2, TPP, TPPS2a, TPPS4, TMPyP, ZnPc, ZnTPP, etc. [140,141,145-149] should also be 
suitable to label melanosomes, and then for dye-improved photothermal and ultrasonic melanoma therapy. It must be noted that some well-known lysosome probes can also label the Golgi apparatus [150]. Lysosome-labeling PDT dyes that are water insoluble can be delivered within DPPC liposomes to enter live cells, increasing selective uptake into tumor cells [151]. Regarding porphycenes, as the double N-protonation of the Po core at low $\mathrm{pH}$ is possible, some amount of TPPo could remain trapped in lysosomes as a dication [141,152].

The selective AO labeling of cultured canine OL melanoma cells (Figure 15), illustrates the strong metachromatic labeling of melanosomes (and lysosomes). It is worth to note that $\mathrm{AO}$ uptake in both organelles depends on the low $\mathrm{pH}$, but dye aggregation occurs due to its high concentration in lysosomes, and to massive dye binding to eumelanin in melanosomes.

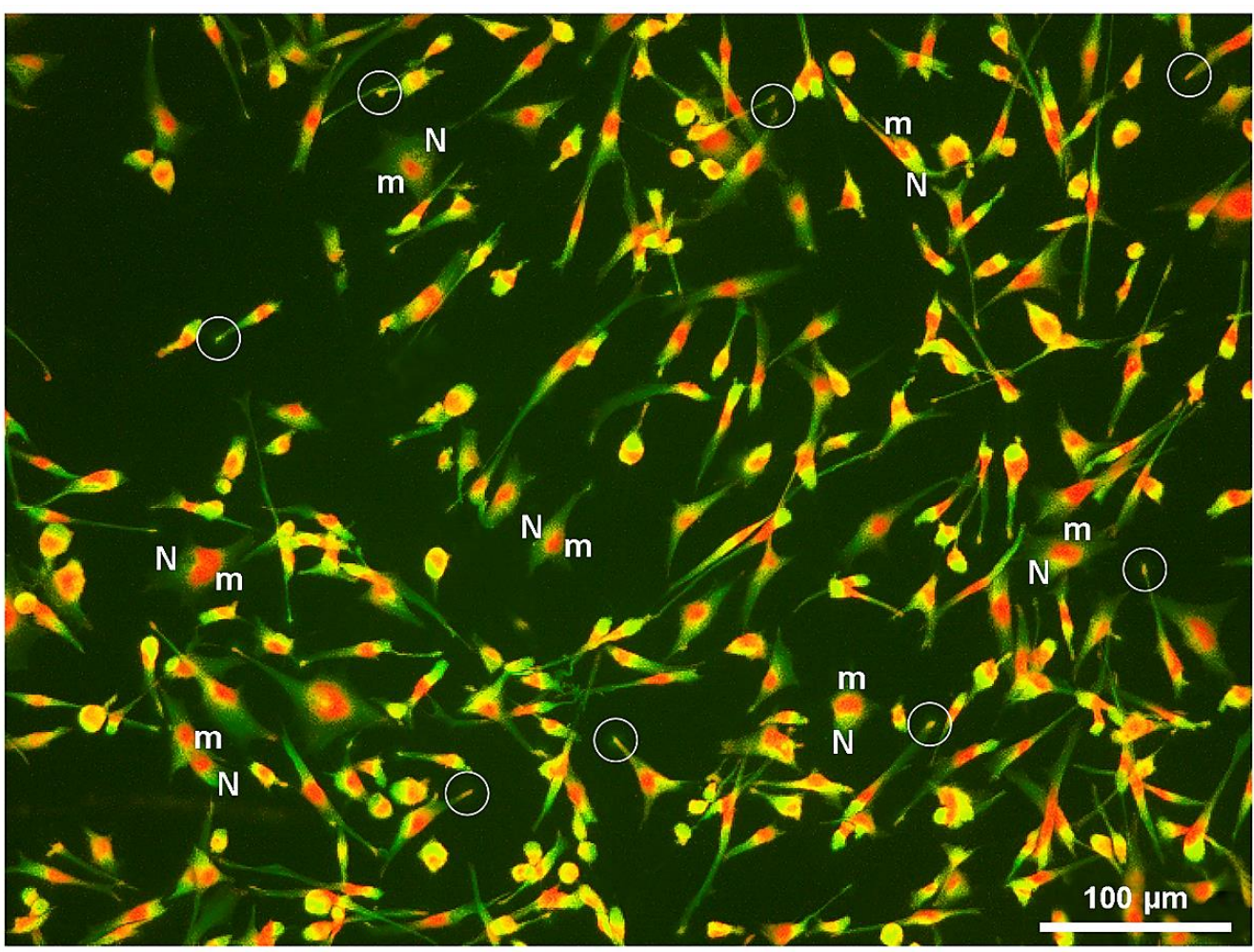

Figure 15. Cultured OL living cells from the oral canine melanotic melanoma [153] grown at semiconfluence and labeled by acridine orange $(50 \mu \mathrm{g} / \mathrm{mL}$ in complete DMEM for $10 \mathrm{~min}$, followed by washing and observation after mounting in PBS). Observe the fusiform and dendritic morphology of tumoral melanocytes, orthochromatic (green) nuclei $(\mathrm{N})$ and cytoplasm with massive accumulation of metachromatic (red) melanosome-containing regions $(\mathrm{m})$, and melanin labeling at the end of narrow

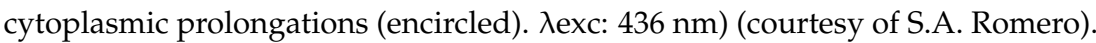

The possible molecular structure and electron orbitals of this colorant bound to eumelanin bis-BQPoe units is shown in Figure 16A,B, as modeled intercalative binding of two $\mathrm{AO}^{+}$into two sheets of the units. Molecular docking indicates that both aromatic acridine rings approach and remain bound face-to-face on one sheet of BQPoe. In the intercalated complex, the fused MOs from LUMO+5 are clearly visible (Figure 16C).

Lysosomes and melanosomes share numerous properties, and when they occur simultaneously, differential identification should involve unshared properties: (a) the brown color of melanosomes characterizes this organelle; (b) silver staining or immunocytochemistry (for tyrosinase or melanosomal proteins) to detect only melanosomes; (c) autofluorescence, which occurs in lysosomes [18] but not in melanosomes. In comparison with melanosomes of skin and skin melanoma, neuromelanin [77], and melanin from RPE are very special 
cases, because they have a complex organization, with melanosomes, lipids, lipofuscin, and melanosomes encased in melano-lipofuscin granules [25].

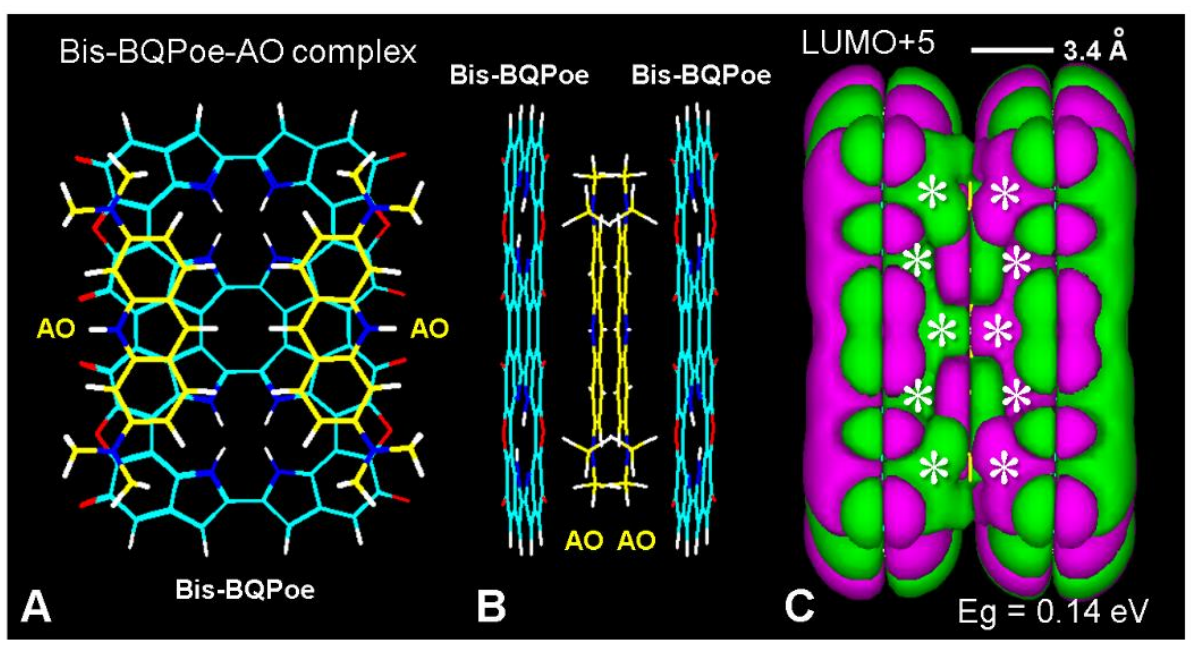

Figure 16. Bis-BQPoe-AO complex. (A): Frontal view of a wire model of two $\mathrm{AO}^{+}$molecules (yellow carbons) intercalated between two bis-BQPoe units (HyperChem v7 software). (B): Lateral view of the complex tilted $7.5^{\circ}$. For other element colors see Figure 4. (C): The corresponding LUMO+5, showing long linear and fused (asterisks) MOs (MM+ method converged to $E=1 \mathrm{kcal} /(\AA \mathrm{mol})$, extended Hückel, Gouraud shaded 3D isosurface, orbital contour: 0.0001).

Macrocyclic colorants are also suitable to fit tightly between eumelanin layers of the poly-BQPo model, allowing to develop fused LUMOs [33,47]. The possible intercalative binding of TPPo into two BQPoe units is shown in Figure 17A,B. When MOs are analyzed, the fused LUMO pattern is clearly observed (Figure 17C). Although different in shape, fused LUMOs of intercalated TPPo-BQPoe eumelanin also occur at many other energy levels.
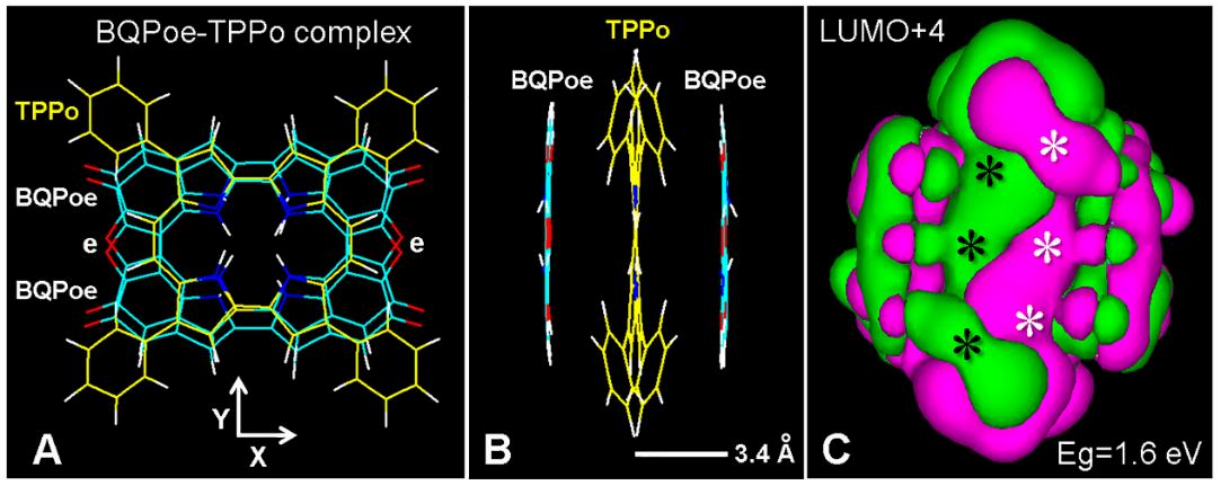

Figure 17. BQPoe-TPPo intercalation complex. (A,B) Frontal and lateral view, respectively, of a wire model of the possible intercalation complex using HyperChem v7 after PM3 energy optimization converged to $\mathrm{E}=2 \mathrm{kcal} /(\AA \mathrm{mol})$. Carbon atoms of TPPo are yellow; e: ether bridges. For other element colors see Figure 4. (C) Fused LUMO+4, Gouraud 3D isosurface, contour value: 0.0006. Observe both the linear and fused LUMOs. The four non-planar phenyl substituents of TPPo do not appreciatively interfere with the intercalative binding and lead to twisted LUMO fusions (asterisks).

Figure 18 emphasizes the hydrophobic binding mode of two copper phthalocyanine $(\mathrm{CuPc})$ chromophores from the AB dye with three aromatic BQPoe units of this eumelanin model. Obviously, stacked arrays of fused LUMOs permits interactions between successive dye chromophores through MOs coupling with the host eumelanin layers, this feature allowing the metachromatic reaction of intercalated dye monomers. 


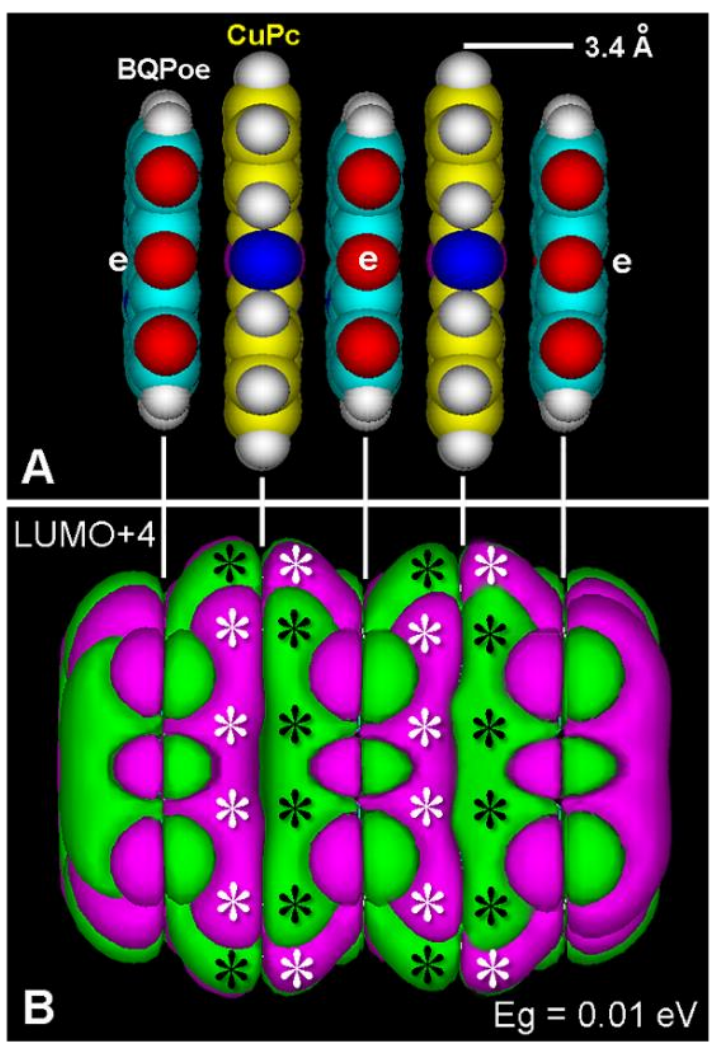

Figure 18. Stacked BQPoe-CuPc complex. (A) Lateral atomic volume view of two copperphthalocyanine rings ( $\mathrm{CuPc}$, yellow carbons) intercalated between three BQPoe units with ether bridges (e), using the HyperChem v7 software after MM+ energy optimization converged to $\mathrm{E}=1 \mathrm{kcal} /(\AA \mathrm{mol})$. For element colors see Figure 4. (B) LUMO+4 of the intercalated CuPc-BQPoe complex (extended Hückel method, Gouraud shaded 3D isosurface, contour: 0.00005, HOMO-0: $\mathrm{E}=-11.36 \mathrm{eV}, \mathrm{LUMO}+0: \mathrm{E}=-11.35 \mathrm{eV}, \mathrm{Eg}=0.01 \mathrm{eV}$ ). Fused LUMOs (asterisks) allow a close $\pi^{*}$ electron coupling between dyes leading to metachromasia. The correspondence of aromatic planes is indicated by vertical white lines.

In the intercalative binding mode, the planar ligands slip between aromatic units of eumelanin layers, and remain trapped as an inclusion complex or "graphitic sandwich", allowing both linear and stacked fused LUMOs [33]. Therefore, massive $\pi^{*}-\pi^{*}$ electron interactions are found in dye-intercalated BQPo or BQPoe model sheets. A schematic diagram of coupled LUMOs is shown in Figure 19. These coupling patterns just occur in aggregated colorants commonly found in tissue histochemistry, leading to a strong metachromatic shift. 


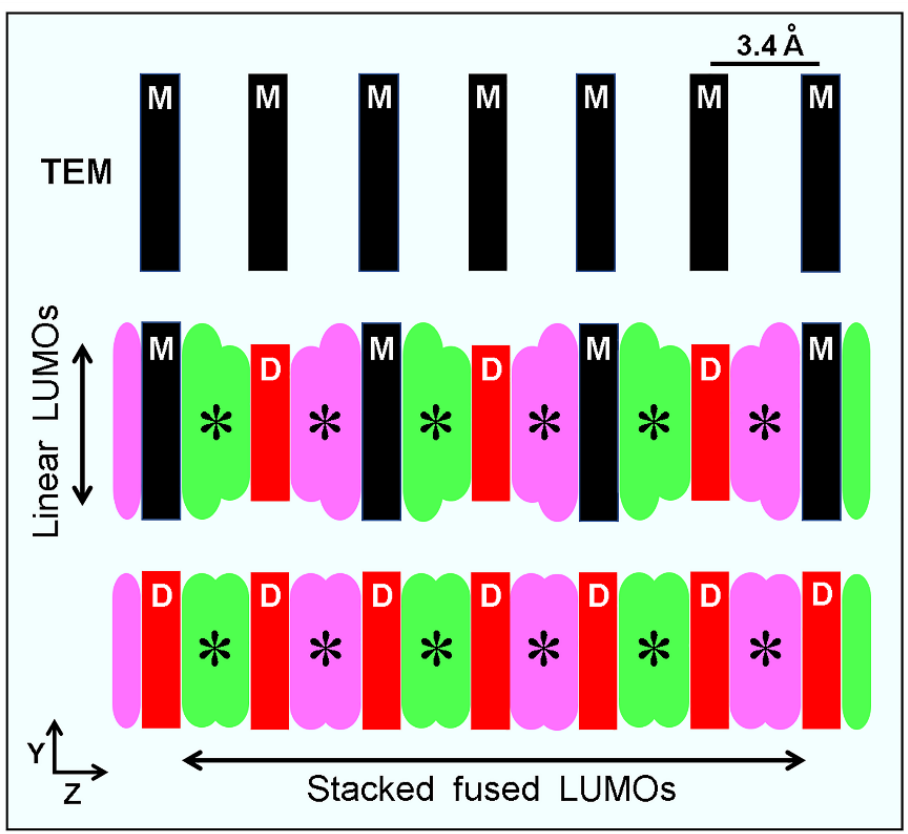

Figure 19. Schematic view of structure-LUMOs correlations. Top: TEM image "equivalent" of graphitic eumelanin layers (M) [62], such as from the poly-BQPoe model, showing the regular $3.4 \AA$ separation of stacked aromatic planes. Middle: Simplified structure and LUMOs from intercalated dyes (D) between eumelanin layers (M), showing linear and fused LUMOs (asterisks). Observe the $\pi^{*}$-electron coupling between colorant molecules through $\pi^{*}$ electrons of aromatic eumelanin layers, leading to metachromatic staining and labeling [33]. Bottom: Stacked chromophores and fused LUMOs (asterisks) are related to a typical metachromatic reaction.

\section{Binding of Colorants and Drugs to Melanin}

Natural and synthetic eumelanins are capable of binding small molecules with high dielectric constants (dimethyl sulfoxide, formamide, methanol), inducing reversible conductivity changes of as much as ten orders of magnitude [154]. Hydrated DOPA-melanin complexed with diethylamine subjected to $10 \mathrm{kHz}$-ultrasound (US) shows a resistivity reduction in $\sim 6$ orders of magnitude [155]. The high affinity of eumelanin for organic compounds allows the establishment of charge-transfer complexes between the pigment (electron acceptor) and the included compound (electron donor), leading to a strongly increased conductivity [80].

High binding affinity of eumelanin for drugs and colorants was found as an unexpected adverse effect of treatments with some neuroleptic and antimalarial drugs. Chronic administration of antidepressant phenothiazines [156,157], and high-dose chloroquine therapy [158] produced chorioretinopathy, suggesting an association between toxic effects of drugs and affinity for melanin. Ototoxicity and disturbances of the skin and hair pigmentation were also reported. Drug binding affinity has been calculated in silico by simple free-energy methods [159], as well as by solvation energy relationships [160], in vitro-in vivo correlations [161], and microscale thermophoresis [162].

Using biochemical analysis, typical colorants, drugs and chemicals have been found to bind strongly to melanin [74,163-174]. Among these melanin-binding ligands, colorants are acridine orange, methyl orange, Biebrich scarlet, Bismarck brown Y, Congo red, Buffalo black NBR, methylene blue, thionine, toluidine blue, fluorescein, neutral red, neutral violet, safranine $\mathrm{O}$, Janus green $\mathrm{B}$, Nile blue A, bromophenol blue, malachite green, fast green FCF, alizarin red S, primulin, tetramethyl-p-phenylenediamine, etc. $[159,163]$. Most of these colorants are also selective probes for lysosome labeling.

Likewise, numerous drugs from different chemical groups bind strongly to melanin (for references, see [74,163-174]). Examples are: aflatoxin $\mathrm{B}_{1}$, p-aminobenzoic acid, aminoglycoside and tetracycline antibiotics, amitriptyline, aniline, benzamides (e.g., ${ }^{18}$ F-labeled 
picolinamide or nicotinamide derivatives), and antipsychotic and anti-emetic benzamides, benzidine, carcinogenic polycyclic hydrocarbons (benzo(a)pyrene, dimethyl-benz(a)anthracene), chloroquine, chlorpromazine, dexamethasone, diclofenac, fluoro-quinolones, herbicides (paraquat), indole acetic acid, iodoquine, $\mathrm{MPP}^{+}$(1-methyl-4-phenylpyridinium), methotrexate, N-nitrosamines, 2-naphthoic acid, papaverine, timolol), quinine, quinidine, phenothiazines, thiouracil, thioureas, trimethyl-psoralen, etc. Benzamides are also used as melanotropic carriers for cytostatic drugs [171].

Therapeutic uses of melanin-binding agents (named melanin or melanoma "seekers") also have limitations. It has been estimated that $7 \%$ of primary skin melanomas, $13 \%$ of regional lymph-node metastases, and 31\% of distant metastases lack melanin [175]. The occurrence of amelanotic melanomas is a disadvantage, because melanoma seekers do not accumulate in those tumors. However, amelanotic melanomas may contain minor amounts of melanin [176], which could be still sufficient to work as a selective therapeutic target.

Melanin-binding ligands can be related to neurotoxic effects, Parkinsonism, and melanoma induction [170]. Interestingly, some of these ligands are known DNA-intercalators, and analogies between DNA- and melanin-binding modes have been pointed out [165]. Among the wide collection of melanin-binding ligands, numerous aromatic compounds are obvious candidates for an intercalative binding mode, according to the models already mentioned (see Figures 16-18). Thiazine ligands (almost planar promethazine and chlorpromazine, with ring torsion angle of $\sim 20^{\circ}$ ), and planar methylene blue bind strongly to melanin, likely by intercalation.

Interestingly, the ability to label melanosomes can be profited by using radionuclidecontaining colorants or agents in therapeutic protocols for advanced melanomas [177]. Binding of radionuclide-labeled dyes and drugs to eumelanin has been applied for melanoma diagnosis and therapy $[166,174,178-180]$. It is worth to note that in classical studies on melanin-bearing tissues (melanomas, uveal tract, hair follicles), whole body autoradiography has shown labeling after administration of radioactive chloroquine and chlorpromazine [166].

Radioactive ligands such as ${ }^{35} \mathrm{~S}$-methylthionine bromide, ${ }^{125} \mathrm{I}$ - and ${ }^{211}$ At-methylene blue have been used to irradiate pigmented melanoma in animal models [179,181,182]. Mono- and di-radioiodinated methylene blue [183], and ${ }^{125}$ I-radiolabeled acridine and acridone derivatives [184] have also been used. ${ }^{125}$ Iodine and ${ }^{211}$ Astatine are Auger-electron and alfa-particle emitters, respectively.

Several compounds with a thioureylene group (e.g., thiouracil and 6-alkyl derivatives, thioureas, methimazole) are incorporated into melanin during its synthesis, and thiouracil derivatives such as ${ }^{125} \mathrm{I}-5$-iodo-2-thiouracil, ${ }^{35} \mathrm{~S}$-2-thiouracil, and ${ }^{10} \mathrm{~B}-5$-dihydroxyboryl-2thiouracil have been applied as selective tumor seekers for radio-scanning diagnosis or treatment of malignant melanoma and metastasis $[169,180]$, in the latter case using slow neutron irradiation. Targeted radiotherapy of pigmented melanoma using ${ }^{131}$ I-labeled picolinamide agents has been carried out [185]. An interesting review has been published on imaging of melanoma metastases with the positron emitter ${ }^{15} \mathrm{~F}$ attached to melanotropic carriers [186].

Likewise, targeting of melanocytes in vitro and in vivo has been achieved using octapeptide derivatives of $\alpha$-melanocyte-stimulating hormone ( $\alpha$-MSH) for binding to the specific receptor MC1R, containing either a chelator for ${ }^{111} \mathrm{In},{ }^{67 / 68} \mathrm{Ga}$ or ${ }^{90} \mathrm{Y}$ (allowing accumulation of radioactivity in experimental melanomas) [187], or a photosensitizer (methylene blue or pyropheophorbide derivative) for PDT [188]. Finally, due to its high ability to retain heavy metals, selective melanin seekers could be simple radionuclide cations for direct binding to $\mathrm{O}$ or $\mathrm{N}$ atoms of the pigment.

\section{Melanoma and Ultrasound Therapy}

On the other hand, using ultrasound (US) microscopy at frequencies near $1 \mathrm{GHz}$, the comparison of iris tissue from albino and pigmented rabbits showed that melanin is a particularly strong acoustic attenuator at those frequencies. In addition, other high US- 
absorbing structures are cell nuclei, rod and cone outer segments, and red blood cells [189]. Acoustic waves can traverse longer distances than photons in condensed matter, and as such, penetration of US into deep tissues can be orders of magnitude higher than light. Accordingly, targeting and therapy of melanomas subjected to sono-sensitizers (SSs) and US treatments show good responses and promising perspectives. Taking into account the binding of numerous ligands to melanin and the strong photonic and US absorption of this pigment, it seems logical to expect an improved photothermal and ultrasono-activity.

An emerging approach for the therapy of tumors and atherosclerosis has been called sonodynamic therapy (SDT), which involves the use of a SS followed by exposure to low intensity US [48,190,191]. As SDT generates damaging ROS and radicals, a more appropriate denomination for this modality should be "sono-electrochemical therapy" (SET), to avoid the misleading use of the term "dynamic" [33]. Employed US parameters for SET are $\sim 1-2 \mathrm{MHz}$ frequencies and $\sim 0.5-10 \mathrm{~W} / \mathrm{cm}^{2}$ energy densities [192].

Berberine, curcumin, hypericin, and protoporphyrin IX are natural SSs with increasing importance [190,191]. Regression of experimental B16 melanoma has been achieved using several SSs such as $\mathrm{TiO}_{2}$ nanoparticles, chloro-aluminum phthalocyanine disulfonate, rose Bengal, and nickel ferrite/carbon nano-composites (NiFeO/C), revealing that SET may be more effective than PDT in treating advanced melanotic melanomas [48]. $\mathrm{TiO}_{2}$ nanoparticles subjected to US $\left(1 \mathrm{MHz}, 1 \mathrm{~W} / \mathrm{cm}^{2}, 2 \mathrm{~min}\right)$ produced significant regression of the C32 melanoma [193]. It is tempting to assume that generic biomembranes and lysosome uptake of nanoparticles [138], and piezoelectric activity of $\mathrm{TiO}_{2}$ are involved in the therapeutic response. As xanthene colorants accumulate into lysosomes, it would be expected that rose Bengal could also label melanosomes. It is noteworthy realizing that the strong US-absorbing eumelanin from melanomas is just a highly suitable endogenous SS for SET itself.

Melanocytes are killed in vitro by US (phonons) in proportion to their melanosome content [194]. Melanin-binding drugs and colorants induce additional toxicity in melanocytes subjected to US, and cell damage increases sharply with temperature, from 7 to $37^{\circ} \mathrm{C}$. The absorption coefficient of melanin exposed to 1-MHz US increases and reaches a value approaching maximal absorption at $60{ }^{\circ} \mathrm{C}$. Absorbed US converts the mechanical phonon energy into cytotoxic products through phonon-electron interactions within the melanosome [194]. In early experiments, cultured melanotic tumor cells treated with chlorpromazine were preferentially killed by $10 \mathrm{kHz}$ US irradiation [155], with radical production and DNA damage. Likewise, $1 \mathrm{MHz}-\mathrm{US}$ induced melanin degradation and death of melanin-containing cells, which were potentiated by previous treatment with melanin-binding drugs such as chlorpromazine and kanamycin [194,195].

Therefore, the concept of melanin as an inert biopolymer is in conflict with the experimental evidence that it is an unusually efficient energy conversion medium with possible biological implications, and capable of cytoprotective as well as cytotoxic action. Cytoprotection is observed with the conversion of photons or excited-state energy of free radicals into phonons. Cytotoxic effects are achieved by driving this process in reverse. In keeping with these facts, electron-phonon interactions are known [196,197]. A photon-electronphonon coupling model for energy interactions in melanin and ligand-bound melanin is shown in Figure 20. 


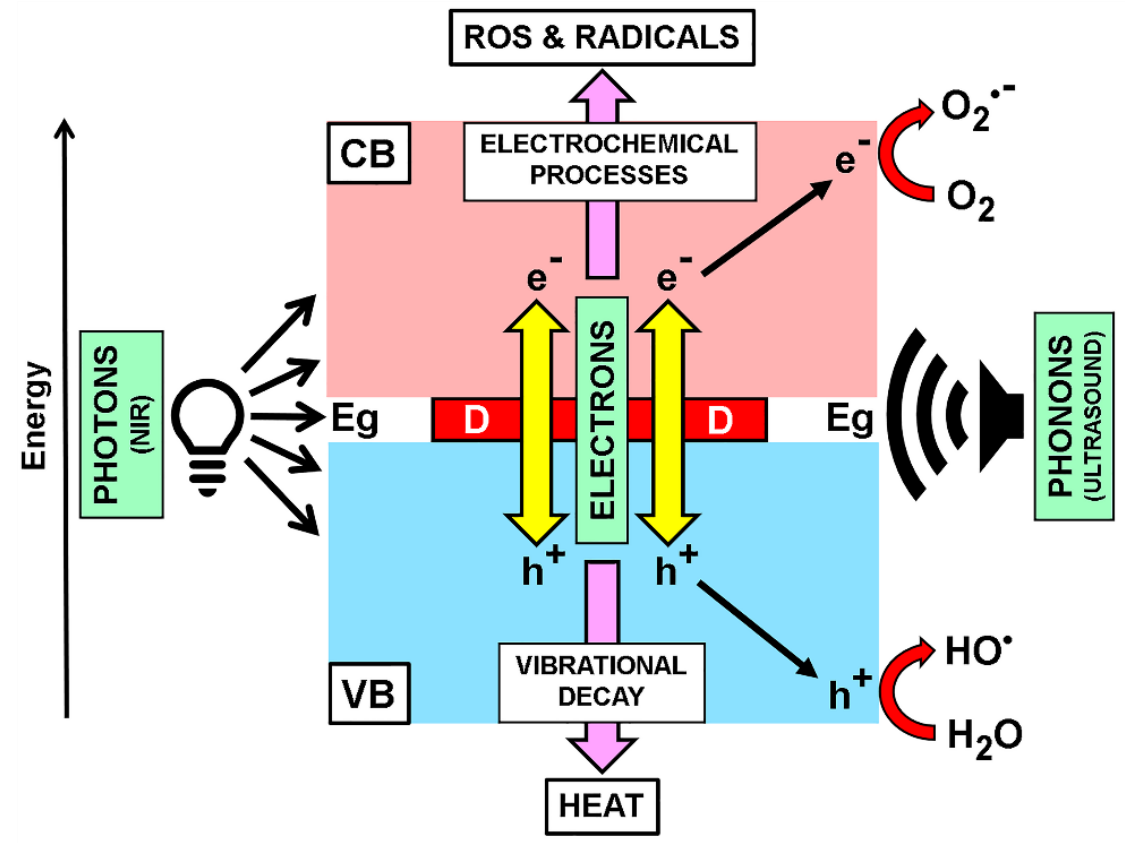

Figure 20. Photon-electron-phonon interaction model in eumelanin. Schematic view of the possible photon-electron-phonon coupling for energy interactions in dye-intercalated eumelanin complexes, inspired in concepts from Corry et al. [155], Kono et al. 1979 [194], Crippa et al. [197], Migliaccio et al. [198], and Sharma and Das [199]. The energy gap (Eg) between VB and CB of eumelanin is occupied by a symbolically intercalated dye (D) that reduces Eg. Energy decay of photo- or US-excited $\pi$ electrons causes vibrational (heat) or electrochemical processes involving electrons $\left(\mathrm{e}^{-}\right)$and holes $\left(\mathrm{h}^{+}\right)$, which participate in photo (electro) catalytic redox reactions. Reduction in $\mathrm{O}_{2}$ to superoxide radical $\left(\mathrm{O}_{2}{ }^{\bullet-}\right)$ and $\mathrm{H}_{2} \mathrm{O}_{2}$ proceeds under oxygenated conditions. All these ROS and radicals generate cell damage and death (Reproduced from the Open Access reference [33]).

Therefore, melanin-, melanin/ligand-based SET, and melanin/lanthanide-based UShyperthermia could represent new, elegant, and non- or minimally invasive therapies for melanoma.

\section{Biomedical Perspectives}

At present there are important advances in imaging and therapeutic protocols for melanomas and neurologic diseases using properties of melanin and melanin-like nanoparticles [32,78,200-202]. A better knowledge of melanin structure and binding capacity toward colorants and drugs will be surely reflected in understanding mechanistic aspects of drug-induced pathological processes, leading to a progress of new biophysical approaches for photodynamic, photothermal, and ultrasonic therapy of melanomas. In this review, we have described molecular modeling advances (mainly planar BQPo and spiral BQPoe models) to explain the chemical organization of eumelanin, as well as the possible intercalation of colorants into graphitic eumelanin layers. These processes result in linear and fused LUMOs in melanin-dye complexes, allowing photon-electron-phonon interactions, and leading to metachromatic staining and labeling of melanosomes. Features based on US-absorbing melanin-ligand complexes induce biological and antitumoral effects, in agreement with previous proposals [33,47].

If corroborated by further studies, these novel conceptions may open interesting perspectives and efficient strategies regarding melanoma therapy, as well as innovative developments with potential biomedical and biotechnological applications. Regarding melanin affinity and melanoma seekers, it is conceivable that the great quantity of catechol groups makes eumelanin a suitable substrate to form borate esters [18]. When the isotope ${ }^{10} \mathrm{~B}$ is used and then irradiated with slow neutrons, the products of the nuclear fission $\left({ }^{7} \mathrm{Li}\right.$ and ${ }^{4} \mathrm{He}$ nuclei) due to neutron capture could damage specifically melanoma cells 
because of their very short braking distance in condensed matter. In keeping with this, a borate ester of DOPA [203] has been proposed as a possible precursor of melanin for ${ }^{10} \mathrm{~B}$ neutron-capture therapy of melanoma.

Regarding dye-melanin interaction, suitable molecular fitting should be a relevant factor: most colorants that label lysosomes also bind to melanin, and could also intercalate between its aromatic layers. In particular, possible intercalative binding of the porphycene dyes TPPo and PdTPPo with melanin would be based on the excellent geometrical matching of these ligands with the BQPo model for eumelanin (see Figure 17), because the host unit and the ligand dyes have the same porphycene ring.

Hypericin induces a necrotic mode of cell death in pigmented melanoma cells and melanocytes (possibly due to the release of toxic melanin precursors from melanosomes), as well as apoptosis in non-pigmented melanoma cells and keratinocytes [204]. Taking into account the aromatic structure of hypericin, it is tempting to speculate that its lysosomal localization [205] could allow uptake and intercalative binding to melanin also in melanosomes. Colorants from acridine, thiazine, xanthene, azine, oxazine, porphyrin, phthalocyanine, and other groups are also well suited to intercalate into graphitic melanin layers. In all these cases of melanin-colorant interactions, an enhanced biological response of melanoma cells and tumors would be expected to occur. Therefore, better understanding of the molecular structure of melanin, as well as binding possibilities and melanin staining and labeling mechanisms, will surely improve the rationale and efficiency of PDT, PTT, and SET protocols for melanoma therapy.

Author Contributions: The authors confirm contributions to the manuscript as follows: Conceptualization, Design, Writing, Figure Preparation, Review and Editing, J.C.S., J.E. and A.B.-C. All authors have read and agreed to the published version of the manuscript.

Funding: The authors received no specific funding for this study.

Institutional Review Board Statement: Not applicable.

Informed Consent Statement: Not applicable.

Data Availability Statement: Not applicable.

Acknowledgments: We thank J.L. Bella, P. Cardozo, M.C. Carou, L.L. Colombo, M. Diamont, D.M. Lombardo, S. Nonell, M.F. Pozzi, S.A. Romero, A. Stockert, and A.J. Urtreger for valuable collaboration.

Conflicts of Interest: The authors declare no conflict of interest.

\section{References}

1. Towns, A. Colorants: General survey. Phys. Sci. Rev. 2019, 4, 1-17. [CrossRef]

2. Harriman, A. Colorants: A new journal bringing colour to life. Colorants 2022, 1, 1-2. [CrossRef]

3. Wainwright, M. The use of dyes in modern biomedicine. Biotech. Histochem. 2003, 78, 147-155. [CrossRef] [PubMed]

4. Green, F.J. The Sigma-Aldrich Handbook of Stains, Dyes and Indicators; Aldrich Chemical Company: Milwaukee, WI, USA, 1990.

5. Horobin, R.W.; Kiernan, J.A. Conn's Biological Stains. A handbook of Dyes, Stains and Fluorochromes for Use in Biology and Medicine, 10th ed.; Bios Scientific Publishers: Oxford, UK, 2002.

6. Whitby, G.S. Dyes and dye chemistry fight disease. Text. Colorist 1942, 64, 119-121.

7. Lillie, R.D. H.J. Conn's Biological Stains, 9th ed.; Williams \& Wilkins: Baltimore, MD, USA, 1977.

8. Kafarski, P.; Lipok, M. Structural analogy—Direct similarity versus topographical complementarity. In Drug Discovery and Development. From Molecules to Medicine; Vallisuta, O., Ed.; IntechOpen Book Series; IntechOpen Limited: London, UK, 2015; Chapter 11. [CrossRef]

9. Vennerstrom, J.L.; Makler, M.T.; Angerhofer, C.K.; Williams, J.A. Antimalarial dyes revisited: Xanthenes, azines, oxazines, and thiazines. Antimicrob. Chemother. 1995, 39, 2671-2677. [CrossRef] [PubMed]

10. Denny, W.A. Acridine derivatives as chemotherapeutic agents. Curr. Med. Chem. 2002, 9, 1655-1665. [CrossRef]

11. Wagner, S.J.; Skripchenko, A. Investigation of photosensitizing dyes for pathogen reduction in red cell suspensions. Biotech. Histochem. 2003, 78, 171-177. [CrossRef] [PubMed]

12. Sugden, J.K. Photochemistry of dyes and fluorochromes used in biology and medicine: Some physicochemical background and current applications. Biotech. Histochem. 2004, 79, 71-90. [CrossRef] [PubMed]

13. Steverding, D. The development of drugs for treatment of sleeping sickness: A historical review. Paras. Vect. 2010, 3, 15. [CrossRef] [PubMed] 
14. Dapson, R.W. Dye-tissue interactions: Mechanisms, quantification and bonding parameters for dyes used in biological staining. Biotech. Histochem. 2005, 80, 49-72. [CrossRef]

15. Prentø, P. Staining of macromolecules: Possible mechanisms and examples. Biotech. Histochem. 2009, 84, 139-158. [CrossRef]

16. Stockert, J.C.; Abasolo, M.I. Inaccurate chemical structure of dyes and fluorochromes found in the literature can be problematic for teaching and research. Biotech. Histochem. 2011, 86, 52-60. [CrossRef] [PubMed]

17. Horobin, R.W.; Stockert, R.W.; Rashid-Doubell, F. Uptake and localization mechanisms of fluorescent and colored lipid probes. Part 2. QSAR models that predict localization of fluorescent probes used to identify ("specifically stain") various biomembranes and membranous organelles. Biotech. Histochem. 2015, 90, 241-254. [CrossRef] [PubMed]

18. Stockert, J.C.; Blázquez-Castro, A. Fluorescence Microscopy in Life Sciences; Bentham Science Publishers: Sharjah, United Arab Emirates, 2017. [CrossRef]

19. D'Ischia, M.; Wakamatsu, K.; Cicoira, F.; di Mauro, E.; Garcia-Borron, J.C.; Commo, S. Melanins and melanogenesis: From pigment cells to human health and technological applications. Pig. Cell Melan. Res. 2015, 28, 520-544. [CrossRef] [PubMed]

20. D'Alba, L.; Shawkey, M.D. Melanosomes: Biogenesis, properties, and evolution of an ancient organelle. Physiol. Rev. 2019, 99, 1-19. [CrossRef] [PubMed]

21. Solano, F. Melanins: Skin pigments and much more-Types, structural models, biological functions, and formation routes. New J. Sci. 2014, 2014, 498276. [CrossRef]

22. Zhou, X.; McCallum, N.C.; Hu, Z.; Cao, W.; Gnanasekaran, K.; Feng, Y.; Stoddart, J.F.; Wang, Z.; Gianneschi, N.C. Artificial allomelanin nanoparticles. ACS Nano 2019, 13, 10980-10990. [CrossRef] [PubMed]

23. Edelstein, L.M. Melanin: A unique biopolymer. Pathobiol. Annu. 1971, 1, 309-324. [PubMed]

24. Swan, G.A. Structure, chemistry, and biosynthesis of the melanins. Forts. Chem. Organ. Naturs. 1974, 31, 522-582.

25. Simon, J.D.; Hong, L.; Peles, D.N. Insights into melanosomes and melanin from some interesting spatial and temporal properties. J. Phys. Chem. B 2008, 112, 13201-13217. [CrossRef] [PubMed]

26. Schroeder, R.L.; Double, K.L.; Gerber, J.P. Using sepia melanin as a PD model to describe the binding characteristics of neuromelanin-A critical review. J. Chem. Neuroanat. 2015, 64-65, 20-32. [CrossRef] [PubMed]

27. Scognamiglio, F.; Travan, A.; Turco, G.; Borgogna, M.; Marsich, E.; Pasqua, M.; Paoletti, S.; Donati, I. Adhesive coatings based on melanin-like nanoparticles for surgical membranes. Coll. Surf. B Biointerfaces 2017, 155, 553-559. [CrossRef]

28. Micillo, R.; Panzella, L.; Iacomino, M.; Prampolini, G.; Cacelli, I.; Ferretti, A.; Crescenzi, O.; Koike, K.; Napolitano, A.; d’Ischia, M. Eumelanin broadband absorption develops from aggregation modulated chromophore interactions under structural and redox control. Sci. Rep. 2017, 7, 41532. [CrossRef] [PubMed]

29. Solano, F. Melanin and melanin-related polymers as materials with biomedical and biotechnological applications-Cuttlefish ink and mussel foot proteins as inspired biomolecules. Int. J. Mol. Sci. 2017, 18, 1561. [CrossRef] [PubMed]

30. Cavallini, C.; Vitiello, G.; Adinolfi, B.; Silvestri, B.; Armanetti, P.; Manini, P.; Pezzella, A.; d'Ischia, M.; Luciani, G.; Menichetti, L. Melanin and melanin-like hybrid materials in regenerative medicine. Nanomaterials 2020, 10, 1518. [CrossRef] [PubMed]

31. Mavridi-Printezi, A.; Guernelli, M.; Menichetti, A.; Montalti, M. Bio-applications of multifunctional melanin nanoparticles: From nanomedicine to nanocosmetics. Nanomaterials 2020, 10, 2276. [CrossRef] [PubMed]

32. Blázquez-Castro, A.; Stockert, J.C. Biomedical overview of melanin. 1. Updating melanin biology and chemistry, physico-chemical properties, melanoma tumors, and photothermal therapy. Biocell 2021, 45, 849-862. [CrossRef]

33. Stockert, J.C.; Blázquez-Castro, A. Biomedical overview of melanin. 2. Updating molecular modeling, synthesis mechanism, and supramolecular properties regarding melanoma therapy. Biocell 2022, 46, 1391-1415. [CrossRef]

34. Li, G.; Herlyn, M. Dynamics of intercellular communication during melanoma development. Mol. Med. Today 2000, 6, 163-169. [CrossRef]

35. Orlow, S.J. Melanosomes are specialized members of the lysosomal lineage of organelles. J. Invest. Dermatol. 1995, 105, 3-7. [CrossRef] [PubMed]

36. Raposo, G.; Marks, M.S. Melanosomes-Dark organelles enlighten endosomal membrane transport. Nature Rev. Mol. Cell Biol. 2007, 8, 786-797. [CrossRef] [PubMed]

37. Smith, S.H.; Goldschmidt, M.H.; McManus, P.M. A comparative review of melanocytic neoplasms. Vet. Pathol. 2002, 39, 651-678. [CrossRef] [PubMed]

38. Blois, M.S. Phagocytosis of melanin particles by human epidermal cells in vitro. J. Invest. Dermatol. 1968, 50, 336-337. [CrossRef] [PubMed]

39. Overwijk, W.W.; Restifo, N.P. B16 as a mouse model for human melanoma. Curr. Prot. Immunol. 2000, 39, 20-21. [CrossRef]

40. Cekanova, M.; Rathore, K. Animal models and therapeutic molecular targets of cancer: Utility and limitations. Drug Des. Develop. Ther. 2014, 8, 1911-1922. [CrossRef]

41. Kuzu, O.F.; Nguyen, F.D.; Noory, M.A.; Sharma, A. Current state of animal (mouse) modeling in melanoma research. Cancer Growth Metast. 2015, 8s1, 81-94. [CrossRef]

42. Sniegocka, M.; Podgórska, E.; Płonka, P.M.; Elas, M.; Romanowska-Dixon, B.; Szczygiel, M.; Zijewski, M.A.; Cichorek, M.; Markiewicz, A.; Brozyna, A.A.; et al. Transplantable melanomas in hamsters and gerbils as models for human melanoma. Sensitization in melanoma radiotherapy-From animal models to clinical trials. Int. J. Mol. Sci. 2018, 19, 1048. [CrossRef] [PubMed] 
43. Finocchiaro, L.M.E.; Agnetti, L.; Fondello, C.; Glikin, G.C. Combination of cytokine-enhanced vaccine and chemo-gene therapy as surgery adjuvant treatments for spontaneous canine melanoma. Gene Ther. 2019, 26, 418-431. [CrossRef] [PubMed]

44. Nasiell, K.; Tani, E.; Skoog, L. Fine needle aspiration cytology and immunocytochemistry of metastatic melanoma. Cytopathology 1991, 2, 137-147. [CrossRef]

45. Olivieri, M.; Nicolaus, R.A. Sulla DHI-melanina. Rend. Accad. Sci. Fis. Matem. Napoli 1999, 66, 85-96.

46. Nicolaus, R.A. Perspectives in Melanin Chemistry. 2005. Available online: http://www.tightrope.it/nicolaus/link\%2023.htm (accessed on 7 December 2018).

47. Stockert, J.C. Melanin and melanoma: Updating molecular structure and photothermal therapy. InVet 2021, 23, 1-15. Available online: http:/ / www.fvet.uba.ar/archivos/publicaciones/invet/vol23-1-2021/art-4-vol23-1-2021.pdf (accessed on 15 February 2022).

48. Li, X.Y.; Tan, L.C.; Dong, L.W.; Shen, X.X.; Lu, X.; Zheng, H.; Lu, Y.G. Susceptibility and resistance mechanisms during photodynamic therapy of melanoma. Front. Oncol. 2020, 10, 597. [CrossRef] [PubMed]

49. Cranford, S. The ABCs of review articles. Matter 2021, 4, 1-3. [CrossRef]

50. Prota, G. Pigment Cell Research: What directions? Pigm. Cell Res. 1997, 10, 5-11. [CrossRef] [PubMed]

51. Bridelli, M.G. Self-assembly of melanin studied by laser light scattering. Biophys. Chem. 1998, 73, 227-239. [CrossRef]

52. Micillo, R.; Panzella, L.; Koike, K.; Monfrecola, G.; Napolitano, A.; d'Ischia, M. "Fifty shades" of black and red or how carboxyl groups fine tune eumelanin and pheomelanin properties. Int. J. Mol. Sci. 2016, 17, 746. [CrossRef]

53. Panzella, L.; Ebato, A.; Napolitano, A.; Koike, K. The late stages of melanogenesis: Exploring the chemical facets and the application opportunities. Int. J. Mol. Sci. 2018, 19, 1753. [CrossRef]

54. Liebscher, J.; Mrówczyński, R.; Scheidt, H.A.; Filip, C.; Hădade, N.D.; Turcu, R.; Bende, A.; Beck, S. Structure of polydopamine: A never-ending story? Langmuir 2013, 29, 10539-10548. [CrossRef]

55. Meredith, P.; Sarna, T. The physical and chemical properties of eumelanin. Pigm. Cell Res. 2006, 19, 572-594. [CrossRef]

56. Kaxiras, E.; Tsolakidis, A.; Zonios, G.; Meng, S. Structural model of eumelanin. Phys. Rev. Lett. 2006, 97, 218102. [CrossRef]

57. Meng, S.; Kaxiras, E. Theoretical models of eumelanin protomolecules and their optical properties. Biophys. J. 2008, 94, 2095-2105. [CrossRef] [PubMed]

58. Galvão, D.S.; Caldas, M.J. Theoretical investigation of model polymers for eumelanins. I. Finite and infinite polymers. J. Chem. Phys. 1990, 92, 2630-2636. [CrossRef]

59. Bridelli, M.G.; Crippa, P.R.; Ugozzoli, F. X-ray diffraction studies on melanins in lyophilized melanosomes. Pigm. Cell Res. 1990, 3 , 187-191. [CrossRef] [PubMed]

60. Cheng, J.; Moss, S.C.; Eisner, M. X-ray characterization of melanins-II. Pigm. Cell Res. 1994, 7, 269-273. [CrossRef] [PubMed]

61. Watt, A.A.R.; Bothma, J.P.; Meredith, P. The supramolecular structure of melanin. Soft Matter. 2009, 5, 3754-3760. [CrossRef]

62. Chen, C.T.; Ball, V.; de Almeida Gracio, J.J.; Singh, M.K.; Toniazzo, V.; Ruch, D.; Buehler, M.J. Self-assembly of tetramers of 5,6-dihydroxyindole explains the primary physical properties of eumelanin: Experiment, simulation, and design. ACS Nano 2013, 7, 1524-1532. [CrossRef] [PubMed]

63. Iijima, S. Direct observation of the tetrahedral bonding in graphitized carbon black by high resolution electron microscopy. $J$. Crystal Growth 1980, 50, 675-683. [CrossRef]

64. Ugarte, D. Curling and closure of graphitic networks under electron-beam irradiation. Nature 1992, 359, 707-709. [CrossRef]

65. Diudea, M.V.; Bende, A.; Nagy, C.L. Carbon multi-shell cages. Phys. Chem. Chem. Phys. 2014, 16, 5260-5269. [CrossRef]

66. Kroto, H.W.; McKay, K. The formation of quasi-icosahedral spiral shell carbon particles. Nature 1988, 331, 328-331. [CrossRef]

67. Kroto, H.W. Fullerene cage clusters. The key to the structure of solid carbon. J. Chem. Soc. Faraday Trans. 1990, 86, 2465-2468. [CrossRef]

68. Hamzah, M.A.N.; Johari, Z.; Hamid, F.K.A.; Ahmadi, M.T.; Ismail, R. Geometry effect on graphene nanoscrolls band gap. J. Comput. Theoret. Nanosci. 2013, 10, 581-586. [CrossRef]

69. Khaledian, M.; Ismail, R.; Akbari, E. Band structures of graphene nanoscrolls and their dispersion relation near the Fermi point RSC Adv. 2016, 6, 38753-38760. [CrossRef]

70. Hedayat, S.N.; Ahmadi, M.T.; Sedghi, H.; Goudarzi, H. Quantum transmission modelling in graphene nano scrolls (GNSs) of double barrier. Int. J. New Tech. Res. 2017, 3, 12-19.

71. Norouzi, S.; Fakhrabadi, M.M.S. Nanomechanical properties of single- and double-layer graphene spirals: A molecular dynamics simulation. Appl. Phys. A 2019, 125, 321. [CrossRef]

72. Ahmadi, M.T.; Ahmadi, R.; Nguyen, T.K. Graphene nanoscroll geometry effect on transistor performance. J. Electr. Mater. 2019, 49, 544-550. [CrossRef]

73. Longuet-Higgins, H.C. On the origin of the free radical property of melanins. Arch. Biochem. Biophys. 1960, 86, 231-232. [CrossRef]

74. Büngeler, A.; Hämisch, B.; Strube, O.I. The supramolecular buildup of eumelanin: Structures, mechanisms, controllability. Int. J. Mol. Sci. 2017, 18, 1901. [CrossRef]

75. Zeise, L.; Addison, R.B.; Chedekel, M.R. Bio-analytical studies of eumelanins. I. Characterization of melanin the particle. Pigm. Cell Res. 1992, 3 (Suppl. 2), 48-53. [CrossRef]

76. Zajac, G.W.; Gallas, J.M.; Cheng, J.; Eisner, M.; Moss, S.C.; Alvarado-Swaisgood, A.E. The fundamental unit of synthetic melanin A verification by tunneling microscopy of X-ray scattering results. Biochim. Biophys. General Subj. 1994, 1199, 271-278. [CrossRef] 
77. Zecca, L.; Bellei, C.; Costi, P.; Albertini, A.; Monzani, E.; Casella, L.; Gallorini, M.; Bergamaschi, L.; Moscatelli, A.; Turro, N.J.; et al. New melanic pigments in the human brain that accumulate in aging and block environmental toxic metals. Proc. Nat. Acad. Sci. USA 2008, 105, 17567-17572. [CrossRef]

78. Sulzer, D.; Cassidy, C.; Horga, G.; Kang, U.J.; Fahn, S.; Casella, L.; Pezzoli, G.; Langley, J.; Hu, X.P.; Zucca, F.A.; et al. Neuromelanin detection by magnetic resonance imaging (MRI) and its promise as a biomarker for Parkinson's disease. NPJ Parkinson's Dis. 2018, 4, 11. [CrossRef] [PubMed]

79. Mostert, A.B. Melanin, the what, the why and the how: An introductory review for materials scientists interested in flexible and versatile polymers. Polymers 2021, 13, 1670. [CrossRef]

80. Nicolaus, R.A. Coloured organic semiconductors: Melanins. Rend. Accad. Sci. Fis. Matem. Napoli 1997, 64, 325-360.

81. Meredith, P.; Riesz, J. Radiative relaxation quantum yields for synthetic eumelanin. Photochem. Photobiol. 2004, 79, 211-216. [CrossRef]

82. Reeb, D.; Best, P.B.; Kidson, S.H. Structure of the integument of southern right whales, Eubalaena australis. Anat. Rec. 2007, 290, 596-613. [CrossRef]

83. Gallas, J.M.; Eisner, M. Fluorescence of melanin-dependence upon excitation wavelength and concentration. Photochem. Photobiol. 1987, 45, 595-600. [CrossRef]

84. Kayatz, P.; Thumann, G.; Luther, T.T.; Jordan, J.F.; Bartz-Schmidt, K.U.; Esser, P.J.; Schraermeyer, U. Oxidation causes melanin fluorescence. Invest. Ophthalmol. Vis. Sci. 2001, 42, 241-246. [PubMed]

85. Elleder, M.; Borovanský, J. Autofluorescence of melanins induced by ultraviolet radiation and near ultraviolet light. A histochemical and biochemical study. Histochem. J. 2001, 33, 273-281. [CrossRef]

86. Fernandes, B.; Matamá, T.; Guimaraes, D.; Gomes, A.; Cavaco-Paulo, A. Fluorescent quantification of melanin. Pigm. Cell Melan. Res. 2016, 29, 707-712. [CrossRef] [PubMed]

87. Mosca, L.; De Marco, C.; Fontana, M.; Rosei, M.A. Fluorescence properties of melanins from opioid peptides. Arch. Biochem. Biophys. 1999, 371, 63-69. [CrossRef] [PubMed]

88. Dysli, C.; Wolf, S.; Berezin, M.Y.; Sauer, L.; Hammer, M.; Zinkernagel, M.S. Fluorescence lifetime imaging ophthalmoscopy. Progr. Retin Eye Res. 2017, 60, 120-143. [CrossRef] [PubMed]

89. Sparrow, J.R.; Parish, C.A.; Hashimoto, M.; Nakanishi, K. A2E, a lipofuscin fluorophore, in human retinal pigmented epithelial cells in culture. Invest. Ophthalm. Vis. Sci. 1999, 40, 2988-2995.

90. Huang, Z.; Zeng, H.; Hamzavi, I.; Alajlan, A.; Tan, E.; McLean, D.I.; Lui, H. Cutaneous melanin exhibiting fluorescence emission under near-infrared light excitation. J. Biomed. Opt. 2006, 11, 034010-034016. [CrossRef] [PubMed]

91. Galván, I.; Jorge, A.; Ito, K.; Tabuchi, K.; Solano, F.; Wakamatsu, K. Raman spectroscopy as a non-invasive technique for the quantification of melanins in feathers and hairs. Pigm. Cell Melan. Res. 2013, 26, 917-923. [CrossRef] [PubMed]

92. Falck, B.; Jacobsson, S.; Olivecrona, H.; Rorsman, H. Pigmented nevi and malignant melanomas as studied with a specific fluorescence method. Science 1965, 149, 439-440. [CrossRef] [PubMed]

93. Rost, F.W.D.; Polak, J.M. Fluorescence microscopy and microspectrofluorimetry of malignant melanomas, naevi and normal melanocytes. Virchows Arch. Abt. A Pathol. Anat. 1969, 347, 321-326. [CrossRef]

94. Paul, E. Malignant melanoma and nevocellular nevi. Histogenesis and relationships. Fluorescence-microscopic and catamnestic photographic studies. Norm. Pathol. Anat. 1984, 48, 1-112.

95. Büssow, H.; Baumgarten, H.G.; Hansson, C. The tapetal cell: A unique melanocyte in the tapetum lucidum cellulosum of the cat (Felis domestica L.). Anat. Embryol. 1980, 158, 289-302. [CrossRef]

96. Lee, E.E.L.; Bezanilla, F. Methodological improvements for fluorescence recordings in Xenopus laevis oocytes. J. Gen. Physiol. 2019, 151, 264-272. [CrossRef] [PubMed]

97. He, S.; Song, B.; Li, D.; Zhu, C.; Qi, W.; Wen, Y.; Wang, L.; Song, S.; Fang, H.; Fan, C. A graphene nanoprobe for rapid, sensitive, and multicolor fluorescent DNA analysis. Adv. Funct. Mater. 2010, 20, 453-459. [CrossRef]

98. Benito-Martínez, S.; Zhu, Y.; Jani, R.A.; Harper, D.C.; Marks, M.S.; Delevoye, C. Research techniques made simple: Cell biology methods for the analysis of pigmentation. J. Invest. Dermatol. 2020, 140, 257-268.e8. [CrossRef]

99. Hessler, M.; Jalilian, E.; Xu, Q.; Reddy, S.; Horton, L.; Elkin, K.; Manwar, R.; Tsoukas, M.; Mehregan, D.; Avanaki, K. Melanoma biomarkers and their potential application for in vivo diagnostic imaging modalities. Int. J. Mol. Sci. 2020, 21, 9583. [CrossRef]

100. Thompson, S.W. Selected Histochemical and Histopathological Methods; C.C. Thomas: Springfield, IL, USA, 1996.

101. Joly-Tonetti, N.; Wibawa, J.I.D.; Bell, M.; Tobin, D. Melanin fate in the human epidermis: A reassessment of how best to detect and analyze histologically. Exp. Dermatol. 2016, 25, 501-504. [CrossRef] [PubMed]

102. D' Ischia, M.; Napolitano, A.; Michalczyk-Wetula, D.; Płonka, P.M. Melanin "dust" or "ghost"? Exp. Dermatol. 2016, 25, 505-506. [CrossRef] [PubMed]

103. Ball, V. Impedance spectroscopy and zeta potential titration of dopa-melanin films produced by oxidation of dopamine. Coll. Surf. A 2010, 363, 92-97. [CrossRef]

104. Liu, Y.; Ai, K.; Lu, L. Polydopamine and its derivative materials: Synthesis and promising applications in energy, environmental, and biomedical fields. Chem. Rev. 2014, 114, 5057-5115. [CrossRef] [PubMed]

105. Ruiz-Molina, D.; Saiz Poseu, J.; Busque, F.; Nador, F.; Mancebo, J. The chemistry behind catechol-based adhesion. Ang. Chem. Int. Ed. 2018, 58, 696-714. [CrossRef] 
106. Chen, L.; Malollari, K.G.; Uliana, A.; Sanchez, D.; Phillip, B.; Messersmith, P.B.; Hartwig, J.F. Selective, catalytic oxidations of C-H bonds in polyethylenes produce functional materials with enhanced adhesion. Chem 2021, 7, 137-145. [CrossRef]

107. Sarna, T.; Hyde, J.; Swartz, H. Ion-exchange in melanin: An electron spin resonance study with lanthanide probes. Science 1976, 192, 1132-1134. [CrossRef] [PubMed]

108. Cho, S.; Park, W.; Kim, D.H. Silica-coated metal chelating-melanin nanoparticles as a dual-modal contrast enhancement imaging and therapeutic agent. ACS Appl. Mater. Interf. 2016, 9, 101-111. [CrossRef]

109. Vitiello, G.; Pezzella, A.; Calcagno, V.; Silvestri, B.; Raiola, L.; D’Errico, G.; Luciani, G. 5,6-Dihydroxyindole-2-carboxylic acid-TiO 2 charge transfer complexes in the radical polymerization of melanogenic precursor(s). J. Phys. Chem. C 2016, 120, 6262-6268. [CrossRef]

110. Di Mauro, E.; Xu, R.; Soliveri, G.; Santato, C. Natural melanin pigments and their interfaces with metal ions and oxides: Emerging concepts and technologies. MRS Comm. 2017, 7, 141-151. [CrossRef]

111. Enochs, W.S.; Petherick, P.; Bogdanova, A.; Mohr, U.; Weissleder, R. Paramagnetic metal scavenging by melanin: MR imaging Radiology 1997, 204, 417-423. [CrossRef] [PubMed]

112. Colombo, L.L.; Vanzulli, S.I.; Blázquez-Castro, A.; Sanchez Terrero, C.; Stockert, J.C. Photothermal effect by 808-nm laser irradiation of melanin: A proof-of-concept study of photothermal therapy using B16-F10 melanotic melanoma growing in BALB/c mice. Biomed. Optics Exp. 2019, 10, 2932-2941. [CrossRef] [PubMed]

113. Simpson, M.J.; Wilson, J.W.; Phipps, M.A.; Robles, F.E.; Selim, M.A.; Warren, S. Nonlinear microscopy of eumelanin and pheomelanin with sub-cellular resolution. J. Invest. Dermatol. 2013, 133, 1822-1826. [CrossRef] [PubMed]

114. Stockert, J.C. Cytochemistry of nucleic acids: Binding mechanisms of dyes and fluorochromes. Biocell 1985, 9, 89-131.

115. Whittingham, M.S.; Jacobson, A.J. (Eds.) Intercalation Chemistry; Academic Press: New York, NY, USA; London, UK, 1982.

116. Stockert, J.C.; Cañete, M.; Colman, O.D. Histochemical mechanism for the orthochromatic staining and fluorescence reaction of lignified tissues. Cell. Mol. Biol. 1984, 30, 503-508. [PubMed]

117. Armas-Portela, R.; Stockert, J.C. A reaction mechanism for the orthochromatic staining of polysaccharides: Monomerizing interactions with basic dyes. Cell. Mol. Biol. 1986, 32, 449-453.

118. Lerman, L.S. Acridine mutagens and DNA structure. J. Cell. Comp. Physiol. 1964, 64 (Suppl. 1), 1-18. [CrossRef]

119. Stockert, J.C. Monomerizing effect of caffeine, o-phenanthroline and tannin on cationic dyes: A model system to analyze spectral characteristics of the intercalative binding to nucleic acids. Acta Histochem. 1989, 87, 33-42. [CrossRef]

120. Stockert, J.C.; Gosálvez, J.; Del Castillo, P.; Pelling, C.; Mezzanotte, R. X-ray microanalysis of toluidine blue stained chromosomes: A quantitative study of the metachromatic reaction of chromatin. Histochemitry 1991, 95, 289-295. [CrossRef]

121. Barrera, C.; Mazzolli, A.B.; Pelling, C.; Stockert, J.C. Metachromatic staining of human sperm nuclei after reduction of disulphide bonds. Acta Histochem. 1993, 94, 141-149. [CrossRef]

122. Stockert, J.C.; Lisanti, J.A. Acridine orange differential fluorescence of fast and slow reassociating DNA after in situ DNA denaturation and reassociation. Chromosoma 1972, 37, 117-130. [CrossRef] [PubMed]

123. Hatton, R.A.; Blanchard, N.P.; Stalojan, V.; Miller, A.J.; Silva, S.R.P. Nanostructured copper phthalocyanine-sensitized multiwall carbon nanotubes films. Langmuir 2007, 23, 6424-6430. [CrossRef] [PubMed]

124. Scott, J.E. The molecular biology of histochemical staining by cationic phthalocyanine dyes: The design of replacements for Alcian blue. J. Microsc. 1980, 119, 373-381. [CrossRef]

125. Juarranz, A.; Cañete, M.; Stockert, J.C. Colour differences in the chromatin staining by cuprolinic blue. Zeit. Mikr. Anat. Forsch. $1987,101,532-536$.

126. Tempesti, T.C.; Stockert, J.C.; Durantini, E.N. Photosensitization ability of a water soluble zinc(II) tetramethyltetrapyridino porphyrazinium salt in aqueous solution and biomimetic reverse micelles medium. J. Phys. Chem. B. 2008, 112, 15701-15707. [CrossRef]

127. Juarranz, A.; Stockert, J.C. Monastral fast blue. Cytochemical properties of a reaction product from Alcian blue stained chromatin. Acta Histochem. 1982, 70, 130-134. [CrossRef]

128. Scott, J.E. Alcian blue. Now you see it, now you don't. Eur. J. Oral Sci. 1996, 104, 2-9. [CrossRef] [PubMed]

129. Macii, F.; Arnaiz, C.P.; Arrico, L.; Busto, N.; Garcia, B.; Biver, T. Alcian blue pyridine variant interaction with DNA and RNA polynucleotides and G-quadruplexes: Changes in the binding features for different biosubstrates. J. Inorg. Biochem. 2020, 212, 111199. [CrossRef] [PubMed]

130. Allison, A.C. Effects of drugs and toxic agents on lysosomes. In Interaction of Drugs and Subcellular Compartments in Animal Cells; Campbell, P.N., Ed.; J. \& A. Churchill Ltd.: London, UK, 1968; pp. 218-236.

131. Allison, A.C.; Young, M.R. Vital staining and fluorescence microscopy of lysosomes. In Lysosomes in Biology and Pathology; Dingle, J.T., Fell, H.B., Eds.; North-Holland Publishing Co.: Amsterdam, The Netherlands; London, UK, 1969; Volume 2, Chapter 22; pp. 600-628.

132. Pitt, D. Lysosomes and Cell Function; Longman: London, UK; New York, NY, USA, 1975; pp. $24-26$.

133. Swanson, J. Fluorescent labeling of endocytic comartments. Meth. Cell Biol. 1989, 29, 137-151.

134. Rashid, F.; Horobin, R.W.; Williams, M.A. Predicting the behavior and selectivity of fluorescent probes for lysosomes and related structures by means of structure-activity models. Histochem. J. 1991, 23, 450-459. [CrossRef]

135. Rice, L.; Wainwright, M.; Phoenix, D.A. Phenothiazine photosensitizers. III. Activity of methylene blue derivatives against pigmented melanoma cell lines. J. Chemother. 2000, 12, 94-104. [CrossRef] 
136. Walker, I.; Gorman, S.A.; Cox, R.D.; Vernon, D.I.; Griffiths, J.; Brown, S.B. A comparative analysis of phenothiazinium salts for the photosensitisation of murine fibrosarcoma (RIF-1) cells in vitro. Photochem. Photobiol. Sci. 2004, 3, 653-659. [CrossRef]

137. Blázquez-Castro, A.; Stockert, J.C.; Sanz-Rodríguez, F.; Zamarrón, A.; Juarranz, A. Differential photodynamic response of cultured cells to methylene blue and toluidine blue: Role of dark redox processes. Photochem. Photobiol. Sci. 2009, 8, 371-376. [CrossRef]

138. Horobin, R.W. Can QSAR models describing small-molecule xenobiotics give useful tips for predicting uptake and localization of nanoparticles in living cells? And if not, why not? In Organelle-Specific Pharmaceutical Nanotechnology; Weissig, V., D’Souza, G.G.M., Eds.; Wiley: New York, NY, USA, 2010; pp. 193-206.

139. Espada, J.; Horobin, R.W.; Stockert, J.C. Fluorescent cytochemistry of acid phosphatase and demonstration of fluid-phase endocytosis using an azo dye method. Histochem. Cell Biol. 1997, 108, 481-487. [CrossRef]

140. Stockert, J.C.; Juarranz, A.; Villanueva, A.; Nonell, S.; Horobin, R.W.; Soltermann, A.T.; Durantini, E.N.; Rivarola, V.; Colombo, L.L.; Espada, J.; et al. Photodynamic therapy: Selective uptake of photosensitizing drugs into tumor cells. Curr. Top. Pharmacol. 2004, 8, 185-217.

141. Stockert, J.C.; Cañete, M.; Juarranz, A.; Villanueva, A.; Horobin, R.H.; Borrell, J.I.M.; Teixidó, J.; Nonell, S. Porphycenes: Facts and prospects in photodynamic therapy of cancer. Curr. Med. Chem. 2007, 14, 997-1026. [CrossRef]

142. Niederau, C.; Van Dyke, R.W.; Scharschmidt, B.F.; Grendell, J.H. Rat pancreatic zymogen granules. An actively acidified compartment. Gastroenterology 1986, 91, 1433-1442. [CrossRef]

143. De Lisle, R.C.; Steinberg, R.; Williams, J.A. Zymogen granules of mouse parotid acinar cells are acidified in situ in an ATPdependent manner. Cell Tissue Res. 1988, 253, 267-269. [CrossRef]

144. Stockert, J.C. The horse eosinophil as a model leucocyte for morphological and cytochemical studies. Braz. J. Morphol. Sci. 2005, $22,73-84$.

145. García-Díaz, M.; Nonell, S.; Villanueva, A.; Stockert, J.C.; Cañete, M.; Casadó, A.; Mora, M.; Sagristá, M.L. Do folate-receptor targeted liposomal photosensitizers enhance photodynamic therapy selectivity? Biochim. Biophys. Acta 2011, 1808, 1063-1071. [CrossRef]

146. Villanueva, A.; Durantini, E.N.; Stockert, J.C.; Rello, S.; Vidania, R.; Cañete, M.; Juarranz, A.; Arranz, R.; Rivarola, V. Photokilling of cultured tumour cells by the porphyrin derivative CF3. Anti-Cancer Drug Des. 2001, 16, 279-290.

147. Ruiz-González, R.; Acedo, P.; Sánchez-García, D.; Nonell, S.; Cañete, M.; Stockert, J.C.; Villanueva, A. Efficient induction of apoptosis in HeLa cells by a novel cationic porphycene photosensitizer. Eur. J. Med. Chem. 2013, 63, 401-414. [CrossRef]

148. Boix-Garriga, E.; Acedo, P.; Casadó, A.; Villanueva, A.; Stockert, J.C.; Cañete, M.; Mora, M.; Sagristá, M.L.; Nonell, S. Poly(D,Llactide-co-glycolide) nanoparticles as delivery agents for photodynamic therapy: Enhancing singlet oxygen release and phototoxicity by surface PEG coating. Nanotechnology 2015, 26, 365104. [CrossRef]

149. Valli, F.; García Vior, M.C.; Roguin, L.P.; Marino, J. Oxidative stress generated by irradiation of a zinc(II) phthalocyanine induces a dual apoptotic and necrotic response in melanoma cells. Apoptosis 2019, 24, 119-134. [CrossRef]

150. Rashid-Doubell, F.; Horobin, R.W. Selection of fluorescent Golgi complex probes using structure-activity relationship models. In Biotechnology Applications of Microinjection, Microscopic Imaging, and Fluorescence; Bach, P.H., Ed.; Plenum Press: New York, NY, USA, 1991; pp. 73-78.

151. Ginevra, F.; Biffanti, S.; Pagnan, A.; Biolo, R.; Reddi, E.; Jori, G. Delivery of the tumour photosensitizer zinc(II)-phthalocyanine to serum proteins by different liposomes: Studies in vitro and in vivo. Cancer Lett. 1990, 49, 59-65. [CrossRef]

152. Bossi, A.; Waluk, J.; Yivlialin, R.; Penconi, M.; Campione, M.; Bussetti, G. Porphycene protonation: A fast and reversible reaction enabling optical transduction for acid sensing. ChemPhotoChem 2020, 4, 5264-5270. [CrossRef]

153. Rossi, U.A.; Gil-Cardeza, M.L.; Villaverde, M.S.; Finocchiaro, L.M.E.; Glikin, G.C. Interferon- $\beta$ gene transfer induces a strong cytotoxic bystander effect on melanoma cells. Biomed. Pharmacother. 2015, 72, 44-51. [CrossRef]

154. Filatovs, J.; McGinness, J.; Corry, P. Thermal and electronic contributions to switching in melanins. Biopolymers 1976, 15, $2309-2312$. [CrossRef] [PubMed]

155. Corry, P.M.; McGinness, J.E.; Armour, E. Semiconductor properties of melanins related to preferential killing of melanoma cells. Pigment Cell 1976, 2, 321-326.

156. Kinross-Wright, V. Clinical trial of a new phenothiazine compound: NP-207. Psych. Res. Rep. 1956, 4, 89-94.

157. Burian, H.M.; Fletcher, M.C. Visual functions in patients with retinal pigmentary degeneration following the use of NP 207. AMA Arch. Ophthal. 1958, 60, 612-629. [CrossRef]

158. Hobbs, H.E.; Sorsby, A.; Freedman, A. Retinopathy following chloroquine therapy. Lancet 1959, 274, 478-480. [CrossRef]

159. Raghavan, P.R.; Zane, P.A.; Tripp, S.L. Calculation of drug-melanin binding energy using molecular modeling. Experientia 1990, 46, 77-80. [CrossRef]

160. Lowrey, A.H.; Fameini, G.R.; Loumbev, V.; Wilson, L.Y.; Tosk, J.M. Modeling drug-melanin interaction with theoretical linear solvation energy relationships. Pigm. Cell Res. 1997, 10, 251-256. [CrossRef]

161. Jakubiak, P.; Cantrill, C.; Urtti, A.; Alvarez-Sánchez, R. Establishment of an in vitro-in vivo correlation for melanin binding and the extension of the ocular half-life of small-molecule drugs. Mol. Pharm. 2019, 16, 4890-4901. [CrossRef]

162. Hellinen, L.; Bahrpeyma, S.; Rimpelä, A.K.; Hagström, M.; Reinisalo, M.; Urtti, A. Microscale thermophoresis as a screening tool to predict melanin binding of drugs. Pharmaceutics 2020, 12, 554. [CrossRef]

163. Potts, A.M. Uveal pigment and phenothiazine compounds. Trans. Am. Ophthal. Soc. 1962, 60, 517-552.

164. Blois, M.S. On chlorpromazine binding in vivo. J. Invest. Dermatol. 1965, 45, 475-481. [CrossRef] [PubMed] 
165. Blois, M.S.; Taskovich, L. The reversible binding of some aromatic and cyclic compounds to biopolymers in vitro. J. Invest. Dermatol. 1969, 53, 344-350. [CrossRef] [PubMed]

166. Lindquist, N.G.; Ullberg, S. The melanin affinity of chloroquine and chlorpromazine studied by whole body autoradiography. Acta Pharmacol. Toxicol. 1972, 31, 1-32. [CrossRef] [PubMed]

167. Blois, M.S. The binding properties of melanin: In vivo and in vitro. Adv. Biol. Skin 1972, 12, 65-79. [PubMed]

168. Lindquist, N.G. Accumulation of drugs on melanin. Acta Radiol. Diagnosis 1973, 325, 1-92.

169. Larsson, B.S. Melanin-affinic thioureas as selective melanoma seekers. Melanoma Res. 1991, 1, 85-90. [CrossRef]

170. Larsson, B.S. Interaction between chemicals and melanin. Pigm. Cell Res. 1993, 6, 127-133. [CrossRef]

171. Oltmanns, D.; Eisenhut, M.; Mier, W.; Haberkorn, U. Benzamides as melanotropic carriers for radioisotopes, metals, cytotoxic agents and as enzyme inhibitors. Curr. Med. Chem. 2009, 16, 2086-2094. [CrossRef]

172. Kowalska, J.; Banach, K.; Rok, J.; Beberok, A.; Rzepka, Z.; Wrzesniok, D. Molecular and biochemical basis of fluoroquinolonesinduced phototoxicity-The study of antioxidant system in human melanocytes exposed to UV-A radiation. Int. J. Mol. Sci. 2020, 21, 9714. [CrossRef]

173. Rimpelä, A.K.; Garneau, M.; Baum-Kroker, K.S.; Schönberger, T.; Runge, F.; Sauer, A. Quantification of drugs in distinctly separated ocular substructures of albino and pigmented rats. Pharmaceutics 2020, 12, 1174. [CrossRef]

174. Chen, C.C.; Chen, Y.Y.; Lo, Y.H.; Lin, M.H.; Chang, C.H.; Chen, C.L.; Wang, H.E.; Wu, C.Y. Evaluation of radioiodinated fluoronicotinamide/fluoropicolinamide-benzamide derivatives as theranostic agents for melanoma. Int. J. Mol. Sci. 2020, 21, 6597. [CrossRef] [PubMed]

175. Shaw, H.M.; Balch, C.M.; Soong, S.; Milton, G.W.; McCarthy, W.H. Prognostic histopathological factors in malignant melanoma. Pathology 1985, 17, 271-274. [CrossRef]

176. Sarna, T.; Swartz, H.M. Identification and characterization of melanin in tissues and body fluids. Folia Histochem. Cytochem. 1978, $16,275-286$.

177. Dadachova, E.; Casadevall, A. Melanin as a potential target for radionuclide therapy of metastatic melanoma. Future Oncol. 2005, 1,541-549. [CrossRef]

178. Panasiewicz, J.; Rybakow, Z.; Kaskiewicz, M.; Wiza, J. Preparation of ${ }^{35}$ S labelled methylene blue. Radiochem. Radioanal. Lett. 1978, 33, 397-402.

179. Link, E.; Łukiewicz, S. A new radioactive drug selectively accumulating in melanoma cells. Eur. J. Nucl. Med. 1982, 7, 469-473. [CrossRef]

180. Napolitano, A.; Palumbo, A.; d' Ischia, M.; Prota, G. Mechanism of selective incorporation of the melanoma seeker 2-thiouracil into growing melanin. J. Med. Chem. 1996, 39, 5192-5201. [CrossRef] [PubMed]

181. Link, E.M.; Brown, I.; Carpenter, R.N.; Mitchell, J.S. Uptake and therapeutic effectiveness of ${ }^{125}$ I- and ${ }^{211}$ At-methylene blue for pigmented melanoma in an animal model system. Cancer Res. 1989, 49, 4332-4337.

182. Link, E.M. Targeting melanoma with ${ }^{211} \mathrm{At} /{ }^{131} \mathrm{I}-$ Methylene blue: Preclinical and clinical experience. Hybridoma $1999,18,77-84$. [CrossRef]

183. Sobal, G.; Rodrigues, M.; Sinzinger, H. Radioiodinated methylene blue-A promising agent for melanoma scintigraphy: Labelling, stability and in vitro uptake by melanoma cells. Anticancer Res. 2008, 28, 3691-3696.

184. Gardette, M.; Viallard, C.; Paillas, S.; Guerquin-Kern, J.L.; Papon, J.; Moins, N.; Labarre, P.; Desbois, N.; Wong-Wah-Chung, P.; Palle, S.; et al. Evaluation of two ${ }^{125}$ I-radiolabeled acridine derivatives for Auger-electron radionuclide therapy of melanoma. Invest. New Drugs 2014, 32, 587-597. [CrossRef] [PubMed]

185. Xu, X.; Yuan, L.; Gai, Y.; Liu, Q.; Yin, L.; Jiang, Y.; Wang, Y.; Zhang, Y.; Lan, X. Targeted radiotherapy of pigmented melanoma with ${ }^{131}$ I-5-IPN. J. Exp. Clin. Cancer Res. 2018, 37, 306. [CrossRef]

186. Wei, W.; Ehlerding, E.B.; Lan, X.; Luo, Q.; Cai, W. PET and SPECT imaging of melanoma: The state of the art. Eur. J. Nucl. Med. Mol. Imag. 2018, 45, 132-150. [CrossRef] [PubMed]

187. Froidevaux, S.; Calame-Christe, M.; Tanner, H.; Sumanovski, L.; Eberle, A.N. A novel DOTA- $\alpha$-melanocytestimulating hormone analog for metastatic melanoma diagnosis. J. Nucl. Med. 2002, 43, 1699-1706.

188. Bigliardi, P.L.; Rout, B.; Pant, A.; Krishnan-Kutty, V.; Eberle, A.N.; Srinivas, R.; Burkett, B.A.; Bigliardi-Qi, M. Specific targeting of melanotic cells with peptide ligated photosensitizers for photodynamic therapy. Sci. Rep. 2017, 7, 15750. [CrossRef] [PubMed]

189. Marmor, M.F.; Wickramasinghe, H.K.; Lemons, R.A. Acoustic microscopy of the human retina and pigment epithelium. Invest. Ophthal. Visual Sci. 1977, 16, 660-666.

190. Kou, J.Y.; Li, Y.; Zhong, Z.Y.; Jiang, Y.Q.; Li, X.S.; Han, X.B.; Liu, Z.N.; Tian, Y.; Yang, L.M. Berberine-sonodynamic therapy induces autophagy and lipid unloading in macrophage. Cell Death Dis. 2017, 8, e2558. [CrossRef] [PubMed]

191. An, Y.W.; Jin, H.T.; Wang, Y.B.; Wang, J.C.; Liu, H.Q. Research progress of berberine mediated photodynamic therapy (Review). Oncol. Lett. 2021, 21, 359. [CrossRef] [PubMed]

192. Abrahamse, H.; Hamblin, M.R. New photosensitizers for photodynamic therapy. Biochem. J. 2016, 473, 347-364. [CrossRef] [PubMed]

193. Harada, Y.; Ogawa, K.; Irie, Y.; Endo, H.; Feril, L.B.; Uemura, T.; Tachibana, K. Ultrasound activation of $\mathrm{TiO}_{2}$ in melanoma tumors. J. Contr. Release 2011, 149, 190-195. [CrossRef]

194. Kono, R.; Yamaoka, T.; Yoshizaki, H.; McGinness, J. Anomalous absorption and dispersion of sound waves in diethylamine melanin. J. Appl. Phys. 1979, 50, 1236. [CrossRef] 
195. McGinness, J.E.; Corry, P.M.; Armour, E. Melanin-binding drugs and ultrasonic-induced cytotoxicity. Pigment Cell 1976, 2, 316-320.

196. Lacy, M.E. Phonon-electron coupling as a possible transducing mechanism in bioelectronics processes involving neuromelanins. J. Theor. Biol. 1984, 111, 201-204. [CrossRef]

197. Crippa, P.R.; Martini, F.; Viappiani, C. Direct evidence of electron-phonon interaction in melanins. J. Photochem. Photobiol. B Biol. 1991, 11, 371-375. [CrossRef]

198. Migliaccio, A.; Gryszel, M.; Đerek, V.; Pezzella, A.; Głowacki, E.D. Aqueous photo(electro)catalysis with eumelanin thin films. Mater. Horiz. 2018, 5, 984. [CrossRef]

199. Sharma, A.; Das, J. Small molecules derived carbon dots: Synthesis and applications in sensing, catalysis, imaging, and biomedicine. J. Nanobiotechnol. 2019, 17, 92. [CrossRef] [PubMed]

200. Zou, L.; Wang, H.; He, B.; Zeng, L.; Tan, T.; Cao, H.; He, X.; Zhang, Z.; Guo, S.; Li, Y. Current approaches of photothermal therapy in treating cancer metastasis with nanotherapeutics. Theranostics 2016, 6, 62-72. [CrossRef]

201. Wang, Y.; You, W.; Li, X. Current status of gene therapy in melanoma treatment. Biocell 2020, 44, 167-174. [CrossRef]

202. Wang, Z.; Peng, H.; Shi, W.; Gan, L.; Zhong, L.; He, J.; Xie, L.; Wu, P.; Zhao, Y.; Deng, Z.; et al. Application of photodynamic therapy in cancer: Challenges and advancements. Biocell 2021, 45, 489-500. [CrossRef]

203. Yoshino, K.; Kotaka, M.; Okamoto, M.; Kakihana, H. ${ }^{11}$ B-NMR study of the complex formation of borate with catechol and L-DOPA. Bull. Chem. Soc. Japan 1979, 52, 3005-3009. [CrossRef]

204. Davids, L.M.; Kleemann, B.; Kacerovská, D.; Pizinger, K.; Kidson, S.H. Hypericin phototoxicity induces different modes of cell death in melanoma and human skin cells. J. Photochem. Photobiol. B Biol. 2008, 91, 67-76. [CrossRef]

205. Theodossiou, T.; Spiro, M.D.; Jacobson, J.; Hothersall, J.S.; MacRobert, A.J. Evidence for intracellular aggregation of hypericin and the impact on its photocytotoxicity in PAM 212 murine keratinocytes. Photochem. Photobiol. 2004, 80, 438-443. [CrossRef] 